Portland State University

PDXScholar

Civil and Environmental Engineering Faculty

Publications and Presentations

$1-1-2008$

\title{
Seasonal Variability and Estuary-Shelf Interactions in Circulation Dynamics of a River-dominated Estuary
}

\author{
Arun Chawla \\ Portland State University \\ David A. Jay \\ Portland State University \\ Antonio M. Baptista \\ Oregon Health \& Science University \\ Michael Wilkin \\ Oregon Health \& Science University \\ Charles Seaton \\ Oregon Health \& Science University
}

Follow this and additional works at: https://pdxscholar.library.pdx.edu/cengin_fac

Part of the Civil and Environmental Engineering Commons

Let us know how access to this document benefits you.

\section{Citation Details}

Chawla, A., Jay, D. A., Baptista, A. M., Wilkin, M., \& Seaton, C. (2008). Seasonal Variability and EstuaryShelf Interactions in Circulation Dynamics of a River-dominated Estuary. Estuaries \& Coasts, 31(2), 269-288.

This Post-Print is brought to you for free and open access. It has been accepted for inclusion in Civil and Environmental Engineering Faculty Publications and Presentations by an authorized administrator of PDXScholar. Please contact us if we can make this document more accessible: pdxscholar@pdx.edu. 


\title{
Seasonal variability and estuary-shelf interactions in circulation dynamics of a river- dominated estuary
}

\author{
Arun Chawla ${ }^{1 *}$, David A. Jay ${ }^{2}$, António M. Baptista ${ }^{3}$, Michael \\ Wilkin $^{3}$ and Charles Seaton ${ }^{3}$ \\ ${ }^{1}$ National Center for Environmental Prediction \\ Environmental Modeling Center \\ Camp Springs MD 20746 \\ Email:arun.chawla@noaa.gov \\ Ph:301-763-8000 x 7209 \\ ${ }^{2}$ Department of Civil \& Environmental Engineering \\ Portland State University \\ Portland OR 97207 \\ djay@cecs.pdx.edu \\ ${ }^{3}$ Science and Technology Center for Coastal Margin Observation and Prediction \\ Oregon Health \& Science University \\ Beaverton OR 97006 \\ * Corresponding author; Ph:301-763-8000 x 7209; Fax:301-763-8545; e-mail:arun.chawla@noaa.gov
}




\section{A. Chawla et al}

Circulation in a river dominated estuary

\section{Abstract}

The long-term response of circulation processes to external forcing has been quantified for the Columbia River estuary using in-situ data from an existing coastal observatory. Circulation patterns were determined from four Acoustic Doppler Profilers (ADP) and conductivity-temperature sensors placed in the two main channels. Due to the very strong river discharge, baroclinic processes play a crucial role in the circulation dynamics, and the interaction of the tidal and subtidal baroclinic pressure gradients plays a major role in structuring the velocity field. The input of river flow and the resulting low-frequency flow dynamics in the two channels are quite distinct. Current and salinity data were analyzed on two time scales - sub tidal (or residual) and tidal (both diurnal and semidiurnal components). The residual currents in both channels usually showed a classical two-layer baroclinic circulation system with inflow at the bottom and outflow near the surface. However this two-layer system is transient and breaks down under strong discharge and tidal conditions, due to enhanced vertical mixing. Influence of shelf winds on estuarine processes were also observed via the interactions with upwelling and downwelling processes and coastal plume transport. The transient nature of residual inflow affects the long-term transport characteristics of the estuary. Effects of vertical mixing could also be seen at the tidal time-scale. Tidal velocities were separated into their diurnal and semidiurnal components using continuous wavelet transforms to acount for the non-stationary nature of velocity amplitudes. The vertical structure of velocity amplitudes were considerably altered by baroclinic gradients. This was particularly true for the diurnal components, where tidal assymetry led to stronger tidal velocities near the bottom. 


\section{Introduction}

Circulation dynamics play a critical role in estuarine physical, chemical and biological transport processes, and a proper understanding of these dynamics provides the baseline for further scientific studies. Theoretical analyses typically assume that circulation processes can be separated into barotropic (laniello 1977, Li and O'Donnell 1997) and baroclinic (Hansen and Rattray, 1965) components, and that these can be quantified separately. Interactions between the tidal and residual flows are, in theoretical treatments, limited or sometimes absent. This approach has proved useful in partially mixed estuaries with weak tidal forcings, where circulation processes are predominantly stationary. However, several studies (Geyer 1988, Simpson et al. 1990, Jay and Smith 1990c, Jay and Musiak 1996, Monismith and Fong 1996) have shown that in river-dominated estuaries, internal tidal asymmetry (ebb-flood asymmetry in density gradients) plays a crucial role in the development of residual currents and important features such as the neap-spring fluctuation in residual flow profiles (Jay and Smith 1990a, 1990b) can only be explained by coupling the barotropic and baroclinic circulation dynamics. The influence of baroclinic processes is not limited to residual scales, with these processes being able to alter the vertical profile of tidal currents as well (Davies, 1993 and Jay and Musiak 1996).

The development of estuarine baroclinic circulation depends on the salinity distribution and the dynamics of salt transport, which in turn are strongly dependent on the circulation. Variable external forcing can then lead to a highly non-stationary environment in river-dominated estuaries where baroclinic circulation forms a significant proportion of the total estuarine circulation. In such systems, circulation dynamics are influenced by a combination of external forcing (winds, river discharge and tides) as well as internal mixing. The variability in transport processes thus depends to a large extent on the variability of the external forcing. The Columbia River estuary illustrates this point very well. Figure 1 shows, for comparable tidal conditions, the salt wedge intrusion into the estuary during the spring freshet for 1997 (which had the strongest freshet since 1974) and 2001, a very low-flow year. During 1997, the flow was four times higher, and the salt wedge intruded less than half as far as in 2001. Horizontal and vertical density gradients are also much sharper during the high flow year. Such sharp density gradients play a 
critical role in circulation processes.

The challenge is to determine how the fluctuations in the external forcing affect circulation in different parts of the estuary. Here, we address three questions:

- What are the seasonal and interannual variations in the tidal and subtidal circulation patterns?

- How do tidal processes affect residual flows and the salinity distribution?

- How do tidal processes vary in response the neap-spring cycle and seasonal variations in river flow?

With the above questions in mind, this study examines long term circulation and salinity records from the Columbia River observatory CORIE (Baptista et al. 1999, Baptista 2006) and identify the important physical processes involved. The study also identifies periods and features of interest for evaluating the skill of complex 3-dimensional estuarine circulation models.

\section{Setting: the Columbia River and Estuary}

The Columbia River system as considered here includes the estuary and tidal river (to the head of the tide at Bonneville dam, km-260) and extends offshore to the continental shelf where the influence of the fresh water plume from the Columbia River can be felt. The estuary itself is shallow and meso-tidal with two main channels - North Channel and South Channel (see Figure 2). These two channels merge about $15 \mathrm{~km}$ from the mouth of the estuary. The South Channel is the main conduit for fresh water discharge through the estuary, while most of the tidal prism empties and fills through the North Channel. As a result the dynamics in the South and North Channel are very different. The Columbia is mesotidal; daily tidal range may vary from less than $2 \mathrm{~m}$ during the neap tides to $\sim 3.6 \mathrm{~m}$ during the spring tides. The tide is mixed, and predominantly semidiurnal with $\mathrm{M}_{2}$ amplitude $\sim 0.95 \mathrm{~m}$ and $\mathrm{K}_{1}$ amplitude $\sim 0.41 \mathrm{~m}$ at the lower estuary.

The Columbia River has second highest annual river discharge in the continental United States (second only to the Mississippi), resulting in a river-dominated estuary. River discharge shows considerable seasonal variability. Flows usually exceed $10,000 \mathrm{~m}^{3} \mathrm{~s}^{-1}$ during the spring freshet months (April-June) and may drop below 2,000 $\mathrm{m}^{3} \mathrm{~s}^{-1}$ during the dry season (July-October). This variability is, 
however, lower than the pre-dam period when discharges varied from 1,000 to $35,000 \mathrm{~m}^{3} \mathrm{~s}^{-1}$ (Bottom et al., 2005). The highest flows in the Columbia River mainstem result from spring snow melt in the interior portion of the Columbia Basin, the lowest occur during very cold winter weather. The interior sub-basin east of the Cascade mountains accounts for $91 \%$ of the surface area of the basin and $\sim 75 \%$ of the flow. The Willamette River and other western tributaries account for the remaining $25 \%$ of the flow. The highest flows are seen after winter rains, with floods occurring as the result of rain-on-snow events. Willamette flows form an appreciable part of the total discharge only from November through April.

Atmospheric forcing is also an important factor in the system. Broadly speaking, a typical year can be divided into three distinct periods. During the winter months from October to March, winds are strong and highly variable, but the strongest winds are from the south and southwest and lead to coastal downwelling. Winter river flows are variable; with the highest flows occurring during brief winter freshets and extreme low flows occurring during very cold periods. The spring freshet period from April to July is characterized by high river discharge. The spring transition from predominantly downwelling-favorable to predominantly upwelling-favorable conditions occurs during this season, usually in June. The summer-fall period from August to November has low to moderate discharge conditions and predominantly northerly winds (leading to upwelling in the coastal zone), typically until mid-October. Within each of these periods we observe characteristic neap-spring variations in response to tidal conditions and considerable variability in wind forcing.

\section{Data and Data Processing}

The multiple, interacting time scales that influence circulation of river-dominated estuaries precludes understanding the complete range of physical processes from short-term process studies alone. To provide insight into seasonal and interannual processes, we rely here on observations from CORIE, an existing observatory designed to observe and predict the Columbia River system on a long-term basis (Baptista et al. 1999, Baptista 2006).

CORIE consists of two components - a real-time monitoring network and a numerical modeling system. The modeling system uses 3D circulation models (e.g., Zhang et al., 2004) to produce daily forecasts and long-term retrospective simulation databases (Baptista et al., 2005). The monitoring network, in place since 1996, consists currently (Baptista 2006) of instrumented stations at $\sim 18$ locations 
inside the estuary (Figure 2) and two offshore locations. CORIE instruments are predominantly of two types - inductive conductivity/temperature instruments (CTDs) that measure the salinity, temperature and pressure at a single depth, and acoustic doppler profilers (ADPs) that measure the velocity profile above the instrument. The extensive temporal records from these stations allow studies of seasonal and interannual variability in ways that have not been possible in the Columbia River in the past.

\section{CORIE Instrument Data}

We focus here on data from the ADPs to resolve currents, and use the salinity data as a measure of transport processes. There are four ADPs in the estuary, at stations am012, am169, red26 and tansy (Figure 2). Three of these stations (am169, red26 and tansy) are located along the South Channel, and are therefore strongly influenced by river discharge. They are, however, located in different water depths. While am169 (instrument depth $=18 \mathrm{~m}$ ) is located near the center of the South Channel, red26 (instrument depth $=16 \mathrm{~m}$ ) is located close to the south edge of the South Channel in a reach where the strongest currents are on the south side of the channel. In contrast, tansy (instrument depth =12 $\mathrm{m}$ ) is south of the main channel, near the mouth of Youngs Bay, where river-bay tidal exchanges add to the complexity of the flow field. In the North Channel there is only one ADP station (am012, instrument depth $=20 \mathrm{~m}$ ), located near the middle of the channel.

The ADPs record time series of velocity in vertical bins with a sampling time step that varied from 1 to 6 minutes. Vertical bins sizes depended on ADP frequency and varied from $0.25 \mathrm{~m}$ to $1 \mathrm{~m}$. In each vertical bin, principal component analysis (Emery and Thomson, 2001) was used to define a coordinate system aligned with the principal axes (directions of maximum and minimum variance). Since the estuary channels are relatively narrow, the velocities along directions of maximum and minimum variance at all depths were essentially the along-channel and across-channel velocities, respectively. At all ADP stations, the across-channel velocity variance is less than $5 \%$ of the along-channel velocity variance. Consequently, all subsequent analyses in this paper have been carried out using the along-channel velocity component only. The most significant potential source of errors in the present ADP data set results from bio-fouling and consequent low signal to noise ratio (SNR) values. A considerable portion of the velocity data in 2002 and isolated sections from other years had to be discarded for this reason. 


\section{A. Chawla et al}

Salinity is determined algorithmically from the CTD sensors from the measured temperature and conductivity of a fixed control volume. Accurate salinity estimates can be obtained as long as the control volume remains unchanged. However, small changes in this control volume can lead to significant errors in salinity estimates, and bio-fouling is the primary source of volume changes. Unlike ADP sensors (where a significant amount of bio-fouling is needed to weaken the acoustic signal appreciably) even small amounts of bio-fouling can have a significant impact on CTD sensors. As a result large, segments of the salinity data were deemed unsuitable for our analyses.

\section{External Data}

Dynamical analyses require external forcing data (tides, river flow, atmospheric conditions) on appropriate time scales. Discharge from Bonneville dam, the most seaward of 13 mainstream dams, was obtained from a USGS gauge. Discharge data from a USGS gauge on the Willamette River (the main coastal tributary of the Columbia River) were used when available (Figure 2). Tidal information is obtained from a NOAA tidal gage located at Tongue Point $(\mathrm{km}-30$, Figure 2). Wind data are determined from an offshore NOAA buoy (46029) located $\sim 40 \mathrm{~km}$ west of the mouth of the Columbia River. In the following analyses we characterize the influence (both direct and indirect) of the different external forcing on circulation processes inside the estuary during these different periods.

\section{Filtering and Low-Frequency Data}

A low-pass filter is used to separate the sub-tidal velocities (hereafter referred to as residual flow) and tidal velocities. The filter is defined in the frequency domain and is given by

$$
\tilde{A}(f)=\left[0.5 *\left(1-\tanh \left(30\left(f-f_{c}\right)\right)\right)\right] A(f)
$$

where $A(f)$ and $\tilde{A}(f)$ are the frequency-domain versions of the original and filtered signals, respectively, and $f_{c}$ is the cut-off frequency for filtering. A hyperbolic tangent function is used to smooth cut-off.

To estimate the variation in the two-layer system, the residual inflow at each of the ADP stations was quantified using an "Inflow Number", defined as: 


$$
\Omega_{i n}=\frac{\sum_{j=1}^{N} \hat{u} \Delta \boldsymbol{Z}}{\sum_{j=1}^{N}\left|u_{j}\right| \Delta \boldsymbol{Z}}
$$

where $N$ is the total number of bins in the vertical direction, $u_{j}$ is the residual velocity (positive values refer to flow moving into the estuary) in the $j^{\text {th }}$ bin, and $\hat{u}$ is the residual inflow velocity given by

$$
\begin{array}{ll}
\hat{u}_{j}=u_{j} & \text { for }\left(u_{j}>0\right) \\
\hat{u}_{j}=0 & \text { for }\left(u_{j}<0\right)
\end{array}
$$

$\Omega_{\text {in }}$ is a dimensionless, proportional inflow, with $\Omega_{i n}=0$ for no inflow and $\Omega_{i n}=1$ for complete inflow. A note of caution is needed regarding the interpretation of the Inflow Number. It is an indication of the proportion of total residual flow over the water column that is flowing into the estuary, not a measure of absolute residual inflow amplitude. $\Omega_{\text {in }}$ is especially useful for comparing stations with different depths and energy levels.

\section{Tides Analysis methods}

Tidal currents in the Columbia River estuary have diurnal, semidiurnal and overtide components, the latter from nonlinear interactions. For analysis of tidal processes, the time series of high-pass-filtered along-channel velocities were further resolved into their spectral components. Here, we focus on the diurnal and semidiurnal components only. The vertical structure of tidal currents is expected to be strongly influenced by changes in stratification and mixing associated with fluctuating river flow and winds, and the fortnightly tidal range variations, yielding non-stationary velocity amplitudes and phases. Thus, continuous wavelet transform (CWT) techniques were used to separate tidal data into their individual spectral components, because they provide information regarding the time evolution of frequency structure. CWT techniques have been successfully applied to oceanographic problems before (e.g. Shen et al., 1994 for wind wave analysis, Panizzo et al., 2002 for studies of land-slide generated waves, and Jay and Flinchem, 1997 and 1999 for tidal analysis).

The wavelet transform of a time series is formed by convolution of the time series with a set of wavelet functions defined by a base (or mother) wavelet. The general transform is given by: 


$$
X_{g}[\tau, \alpha]=\frac{1}{\sqrt{\alpha}} \int_{-\infty}^{\infty} x(t) g_{\alpha \tau}^{*}(t) d t
$$

where, $x(t)$ is the data time series, $\tau$ is the translation parameter, $\alpha$ is the scale dilation parameter and $g_{\alpha \tau}(t)$ is a set of complex wavelet functions defined by $g_{\alpha \tau}(t)=g\left[\frac{(t-\tau)}{\alpha}\right], g(x)$ being the base function. The choice of this base function is somewhat arbitrary, as long as certain properties are satisfied (see Meyers et al., 1993 and Flinchem and Jay, 2000 for details) and is determined by the problem at hand. We have used a "Morlet wavelet" (Emery and Thomson, 2001) as our base function:

$$
g(x)=e^{-x^{2} / 2} e^{i \pi c x}
$$

where $c=2$, so that the dilation parameter $\alpha$ in (4) corresponds to the period of the tidal component that we are trying to resolve. The function $X_{g}[\tau, \alpha]$ in (4) is a complex time series, representing the time-varying amplitude and phase of $x(t)$ at any given frequency.

One of the properties of wavelet transforms is that an increase in spectral resolution is accomplished at the cost of temporal resolution. To optimize temporal resolution, the analysis focuses on the diurnal $(\alpha=$ 1 day) and semidiurnal ( $\alpha=0.5$ day) tidal species rather than on constituents (Flinchem and Jay, 2000). These species were resolved using filters of 61 and $121 \mathrm{hrs}$, respectively. Filters of this length are narrow enough to exclude non-tidal fluctuations while still resolving neap-spring transitions and related variations. Half a filter length of data is discarded at the beginning and end of the transform, to avoid end effects.

\section{Results and Discussion}

As stated in the introduction, we seek to describe the seasonal and interannual variations in tidal and subtidal circulation patterns, define how tidal processes affect residual flows and the salinity distribution, and document the response of tidal currents to the neap-spring cycle and seasonal variations in winds and river flow. To examine sub-tidal processes, we look at CORIE ADP data from April through December of 1997 . These data are particularly valuable because they are relatively complete and cover a large part of a year with the strongest spring freshet since 1974. Unfortunately most of the CTD sensors 
went into operation only in 2001, so salinity data are not available for this period in 1997.

\subsection{Residual Flows}

Prior studies (Hansen and Rattray, 1965; Jay and Musiak, 1996) suggest that the residual flow in the Columbia River is generated by two primary factors: a) mean horizontal density gradients, leading to gravitational circulation, and b) time-varying vertical mixing and stratification, leading to internal tidal asymmetry. Both of these factors, as well as the effects of atmospheric forcing, are evident in the four April to December of 1997 ADP time series of along-channel residual flow shown in Figure 3, though a lack of density structure data precludes a quantitative separation of the various processes.

The residual flow patterns show strong seasonal and tidal monthly variability. A two-layer residual pattern is observed at all stations, but is transient. The alternating establishment and breakdown of twolayer flow under neap and spring tidal conditions was reported by Jay and Smith (1990a). There are however distinctive residual flow patterns at the different stations. Residual inflow is the strongest in the North channel station (am012) since it is the deepest station and least influenced by river discharge (Fain et al, 2000). In the South Channel, the strength of residual inflow is directly related to depth. After the spring freshet (during which salinity and inflow are absent), the most upstream station (am169) records stronger residual inflow velocities than any other South channel station because it lies in the main thalweg, where the density effects are expected to be the strongest. Both depth and inflow are intermediate at red26. The shallow depths at tansy limit the development of gravitational forcing. River outflow occurs throughout the water column during the spring freshet; inflow is weak for the remainder of the record.

Two other factors are of interest at tansy. The first factor is that landward flow, when it is reestablished after the freshet, is not bottom concentrated, but appears at $\sim 5-7 \mathrm{~m}$ depth. This leads to the suspicion that this landward flow is due to internal asymmetry (which may occur anywhere in the water column) rather than gravitational circulation, which increases toward the bed. The second factor is the rather strong neap-spring contrast in residual flow. Because tansy is on the outside of a channel bend, it is likely that the strong ebb currents during spring tides are displaced further to the south than is the case with the weaker ebbs during the neaps, leading to a stronger neap-spring contrast than for a straight channel. Additionally reduced salinity intrusion during spring tides may also reduce inflow. 
The variation in Inflow Number $\Omega_{\text {in }}$ at the four ADP stations is shown in Figure 4, along with daily tidal range (from NOAA tidal gage), daily river discharge (from Bonneville dam) and daily averaged wind speed (at NOAA buoy 46029). During the spring freshet (May and June; flow $>8,000 \mathrm{~m}^{3} \mathrm{~s}^{-1}$ ), residual inflow is observed only at am012 in the North Channel. The strong river outflow through the South channel overcomes the baroclinic inflow and destroys the two-layer flow pattern at all other stations even during the weakest tides. This occurs despite flood salinity intrusion all the way to am012 (Figure 1). Comparing $\Omega_{\text {in }}$ for the South Channel (stations am169, red26 and tansy) with the river flow and tides, we observe that for discharge less than $8,000 \mathrm{~m}^{3} \mathrm{~s}^{-1}$ some inflow is observed at all stations (Figures 4-6). $\Omega_{\text {in }}$ peaks during the neap and decreases to 0 or near zero during the springs (Figure 6). This breakdown of the twolayer residual flow during stronger tides occurs due to an increase in vertical mixing, which weakens the baroclinic flow into the estuary when a critical tidal range is reached (Jay and Smith, 1990b). This neapspring transition, which occurs in the South Channel for all river flows below $\sim 8,000 \mathrm{~m}^{3} \mathrm{~s}^{-1}$, is clearly seen from a scatter diagram of Inflow Numbers vs river discharge (Figure 5).

A similar feature is observed in the North Channel (station am012), but some inflow occurs on neap tides even for the highest flow levels observed $\left(12,000-14,000 \mathrm{~m}^{3} \mathrm{~s}^{-1}\right)$.Station am012 differs from the three South Channel stations because of its greater depth and reduced influence of river discharge. Thus, $\Omega_{i n}>$ 0 in the North Channel during the weak tides, even under high discharge periods. In fact, as the river discharge drops below $8,000 \mathrm{~m}^{3} \mathrm{~s}^{-1}$, residual inflow is observed even during the large tides, and, in contrast to the observations in the South channel stations, $\Omega_{\text {in }}$ actually increases during the larger tides (Figure 6). This occurs because enhanced tidal mixing reduces the salinity near the bottom but increases it near the surface. The residual inflow generated by the density gradients over the water column are strong enough to counteract the weak river outflow at this station, leading to a net residual inflow over a larger part of the water column and an increase in $\Omega_{i n}$, even though the total residual flow into the estuary is usually weaker than during the neap tides.

To compute a quantitative relation between the Inflow Number, river discharge and tidal range, we seek a solution of the form

$$
\hat{\Omega}_{i n}=a_{0} Q^{N 1} R^{N 2}
$$


where $Q$ refers to the river discharge in $10^{3} \mathrm{~m}^{3} \mathrm{~s}^{-1}, R$ the tidal range in $\mathrm{m}$ and $a_{0}, N 1$ and $N 2$ are the curve fitting parameters determined from the data. Figure 6 shows the scatter diagram between Inflow Number and tidal range for the months of July and August, when river discharge and tidal range are the main forcing processes. The black dots indicate the actual data while the red dots correspond to hindcast estimated values derived from solution of (6). The values of the parameters together with goodness of fit estimates $\left(r^{2)}\right.$ are also shown. A significant amount of the scatter in the data can be explained by the combined action of river discharge and tidal range.

As expected moreover, $N 1<0\left(\Omega_{\text {in }}\right.$ decreases with increased river flow $)$ at all stations, and $N 2<0$ in the South Channel $\left(\Omega_{\text {in }}\right.$ decreases with increased tidal range). $|N 1|$ and $|N 2|$ are smallest at am012, indicating that the North Channel is somewhat buffered from changes related to both flow and tidal range. This is consistent with its depth and remoteness for direct river discharge. The low value of $|N 1|$ at red26 is similarly consistent with its seaward position. A relatively high value of $|N 2|$ at am169 is consistent with the fact that this station is close to the upstream limit of salinity intrusion, which is quite sensitive to tidal range. Station tansy has the largest values of both $|N 1|$ and $|N 2|$, whereas one would think that its $|N 1|$ values should be low due to its shallow depth, which reduces gravitational circulation. Large changes in residual flow at tansy due to tidal and river flow variability may be in part related to channel curvature and lateral migration of circulation patterns, not just to changes in vertical mixing.

To summarize, the interaction between tides and river discharge lead to different patterns of residual flow in the two channels. In the South Channel, the classical two-layer residual flow pattern during neap cycles is seen only for low river discharge (below $8,000 \mathrm{~m}^{3} \mathrm{~s}^{-1}$ ) and disappears completely under high river discharge, even when and where salinity intrusion is still present. We deduce, therefore, that landward salt transport under high flow conditions occurs by tidal mechanisms. In the North Channel, a two-layer pattern is seen during neap tides for high river discharge, and at all times during the low river discharge. The total residual inflow in the North Channel is still inversely related to the tidal range (shown) but $\Omega_{\text {in }}$ is larger during spring tides. The absence of density data for this time period preclude any quantitative assessment of the relative roles of gravitational circulation vs. internal asymmetry. However, the data at tansy suggest the presence of internal asymmetry, and Jay and Musiak $(1994,1996)$ have verified its presence at am012 and am169 for a variety of flow conditions, and tidal current patterns suggest its presence at all 
stations (as discussed below). Tidal mechanisms are likely, therefore, to be important in the salt transport, as they are at more seaward transects (Jay and Smith, 1990c; Kay et al. 1996)

Winds also play an important role in the residual flow patterns of the Columbia River estuary. This can be seen by comparing three instances in September, October and November (marked by the dotted vertical lines in Figure 4). All three instances have similar discharge and tidal conditions, but the winds are very different with much stronger N-S and E-W winds during the October and November events respectively. During September we see the development of a two-layer system at am169 (indicated by the non-zero values of the Inflow Number) that grows and slowly disappears as the tides transition from neap to spring conditions. During the October wind event, though a two-layer system is formed, it is not as prominent and its breakdown occurs much more rapidly at all the three South Channel stations (and probably the North Channel station as well). The two-layer flow breaks down even though the tides and river flow are very weak, suggesting that the strong along shore winds during this period influenced the density and residual flow fields.

Similar features are also observed during the November event. Influence of winds on residual transport can occur through three possible processes. One is the direct action of wind-induced turbulence which would break down the two-layer residual flow pattern in a fashion similar to tidal mixing. The second is a deepening of the offshore fresh water plume that can reduce the salt coming in to the estuary from the bottom and hence significantly reduce the baroclinic component of residual inflow. Finally, winds or pressure fluctuations can cause a barotropic surface slope change, which then leads to salt wedge displacement (barotropic adjustment) and a subsequent recovery (baroclinic adjustment) over a period of days. Jay and Smith (1990c) document such an occurrence in December 1981. The change in cross shore wind patterns and the corresponding drop in residual inflow during the November event suggests that a barotropic / baroclinic adjustment process might have occurred.

To explore the role of the first two processes in reducing the residual inflow we need to look at salinity data, which was not available for this period. As a result we examine a different period with similar conditions (high winds, low tides and river discharge) when both salinity and velocity data are available; we see similar phenomena. Figure 7 shows the influence of winds and tides on the salinity and residual inflow from November 2001 through March 2002. Here, time series of the daily maximum salinities at two 
stations near the mouth of the estuary (sandi in the North Channel, and red26 in the South Channel.; Figure 2) were plotted together with the depth integrated residual inflow (at am012), and the external forcing (river discharge, tidal range, and low-passed alongshore wind velocity component). The CTD sensors at sandi and red26 are in shallow water, close to the bottom ( $1 \mathrm{~m}$ above the bottom) in depths of 7.6 and $9 \mathrm{~m}$, respectively (the CTD and ADP sensors at red26 are approximately $100 \mathrm{~m}$ apart, hence the difference in depths at the two sensors). These represent salinity propagation into the estuary near the mid-depth maximum in landward salt transport (Jay and Smith, 1990c; Kay and Jay, 1996). Because we are interested in total rather than proportional inflow, we use the depth-integrated residual inflow instead of $\Omega_{\text {in }}$ to quantify the flow coming into the estuary. Also shown Figure 7 is a time series of sub-tidal elevation at the Tongue Point tide gauge, which reflects the strength of upwelling versus downwelling processes (sub-tidal elevation increases during downwelling), as well as time series of daily minimum salinities from a near surface sensor placed on an offshore buoy (ogi01, located approximately $25 \mathrm{~km}$ South West from the mouth of the estuary). Jay (1984) and Jay and Flinchem (1997) showed that mean elevation at Tongue Point responds primarily to coastal forcing rather than river flow.

From Figure 7 we can discern three intervals (beginning of December 2001, middle of January 2002 and beginning of March 2002) when there is a consistent decreasing trend in maximum salinities near the bottom at red26 and sandi. In all the cases the drop in salinities inside the estuary occur not during the periods of strong winds but some time after it, suggesting that wind induced mixing is not the direct cause of the reduction of salinity; wind forcing is, nonetheless, involved. In the first two events the drop in maximum salinities occurs when the winds change direction from downwelling to upwelling prevalent winds. Downwelling-favorable southerly winds deepen the low salinity plume as well as move the plume to the north away from the mouth of the estuary. When the wind changes direction and the plume is pushed back south towards the mouth of the estuary the reduced offshore salinities propagate into the estuary, leading to a reduction in residual inflow (as seen in the data at am012). The movement of the plume back south is clearly seen in the time series of the daily minimum salinities from the surface CT sensor at ogi01, where there is a significant drop in the daily minimum salinities corresponding with a drop in the maximum salinities in the estuarine stations. Also note that from December 2001 through midway of January 2002 there are three distinct periods of downwelling persistent winds followed by relaxation of 
winds, but that the reduction in estuarine salinity occurs only during the first and third case. Surface salinity data at ogi01 shows that the wind relaxation after the second downwelling event was not significant enough to move the plume back in front of the estuary, thus signifying the importance of plume dynamics in salt propagation inside the estuary. Although consistent time-series data are not available during summer upwelling periods, vessel observations (not shown) indicate that upwelling brings water with $S>33$ into the estuary, reflecting coastal upwelling.

The effect of transitory residual inflow on the salt transport characteristics can be observed in the time series of an upstream CTD station (eliot). This station is located $\sim 40 \mathrm{~km}$ upstream from the mouth of the Columbia River estuary, at a depth of $14.3 \mathrm{~m}$ (see Figure 2); salinity intrusion occurs primarily during lowflow periods. Figure 8 shows the daily maximum salinity at this station over 3 years together with forcing data. In general, salt is observed at eliot only during or just after neap tides, reflecting the stronger nearbed land-bed transport during periods of weak tides (Jay and Smith, 1990a). There are also two seasonal trends: 1) salinity intrusion decreases due to increased river discharge during spring freshets, and 2) a subtler tendency for salinity intrusion to decrease during the winter months when wind effects increase. This is discernible in the winter of $2001(10 / 01-4 / 02)$ and 2003 (10/03 onwards) where salinity at eliot drops during the strong downwelling periods. The recovery in salinity during two neap tides in late December 2002 and early January of 2003 even under strong winds is most probably due to persistent downwelling conditions and consequent inability of the plume to move back towards the mouth of the estuary during periods of wind relaxation. Some of this is seen in the time series of daily minimum salinity at ogi01. Unfortunately this CORIE buoy was lost during a winter storm in December 2002 and the NOAA buoy compass also malfunctioned around this time (zero values for onshore wind velocities) which precludes us from confirming this hypothesis.

To summarize, residual flow fields in the Columbia River estuary show a strong influence of baroclinic processes and are sensitive not only to fluctuations in discharge, but also to alongshore winds (upwelling and downwelling) which changes the salinity of water intruding into the estuary. The net result of the interactions between these three factors is important because residual flow fields play a crucial role in transport characteristics in the upper reaches of the estuary. Due to the seasonal nature of river discharge patterns and shelf winds it is possible to qualitatively separate the influence of each individual external 
forcing. Seasonal features of salt transport are very well captured at both the offshore (ogi01) and upstream (eliot) gages. At the same time there is clear evidence of the coupling between the offshore and estuarine transport processes.

\subsection{Tidal Circulation}

It is useful, before discussing the interaction of tidal and non-tidal processes, to define the properties of tidal currents at the four ADP stations. Figure 9 shows the semidiurnal velocity amplitudes as a function of depth and time for the four ADP stations, for the same time period as in Figure 3. For comparison purposes, time series of semidiurnal elevation amplitude (obtained by performing a similar wavelet transform on the NOAA tidal gage data) together with the winds and the river flow have also been plotted. As expected, maximum current amplitudes generally coincide with maximum spring tides, and the velocity amplitudes at tansy are in general smaller than at the other stations because tansy is located in shallower waters outside the channel.

The vertical structure of semidiurnal velocity amplitude shows some differences between the two channels. In the South Channel, the maximum (in the vertical) velocity amplitudes are near the surface, and the amplitudes decrease near the bottom due to frictional effects. This is expected in a system dominated by barotropic processes. In the North Channel however, we observe that the maximum velocity amplitude is sometimes found lower in the water column. The disparity between the North and South Channels becomes clearer in a scatter diagram comparison between maximum (over depth) semidiurnal velocity amplitudes and corresponding tidal elevation amplitudes (Figure 10). Both red26 and am169 show a relatively tight correlation between elevation amplitude and maximum velocity amplitudes. On the other hand, the correlations at tansy and am012 are lower, especially am012. The lack of strong correlation at tansy may be related to channel curvature, because the station is located in shallower water outside of the salt wedge - as tidal range increases, it appears that the core of the flow moves to the south, closer to tansy. In contrast, the poor correlation between tidal forcing and maximum current amplitudes at am012 is most probably due to baroclinic effects. Also, semidiurnal tidal amplitude at the Tongue Point gauge decreases with increasing flow due to a frictional bed stress interaction between tides and river flow (Kukulka and Jay, 2003), so some decrease in tidal current amplitude with increasing river flow may be expected, but this appears to be small seaward of Astoria. 
Figure 11 shows the plots of diurnal tidal velocity amplitudes for the same time period. As in the semidiurnal flows, the peaks in velocity amplitudes for the diurnal flows generally coincide with corresponding peaks in tidal elevation amplitudes. The ratio of maximum diurnal current amplitude to maximum diurnal height amplitude is near unity (taking red26, with the strongest currents, as an example). This is, perhaps surprisingly, very similar to the ratio of maximum semidiurnal current amplitude to maximum semidiurnal height amplitude at red26, whereas one would expect that the semidiurnal ratio would be about twice the diurnal ratio, because the semidiurnal wave (relative to the diurnal wave) must transport any given tidal prism in half the time. Jay and Musiak (1996) suggest a reason for this apparent anomaly: diurnal currents have a lower ratio of acceleration to friction, changing the wavenumber and wavelength sufficiently to compensate for the difference in period. Nonetheless, both the maximum diurnal and semidiurnal waves have a clear relationship to tidal range.

The vertical structure of diurnal velocity amplitude, on the other hand, shows a fairly complex behavior. In the North Channel (am012), the maximum diurnal velocity amplitudes are located near the bottom with very small values at the surface, which is contrary to what we would expect for barotropic tidal flows. In the South Channel, the vertical structure varies between stations and over time. At red26, the maximum velocity amplitude shifts towards the bed during the high river discharge periods, while at am169 the maximum velocity amplitude shifts towards the bed during the lower river discharge periods. The velocity flow field during spring freshets of 2002 and 1999 (figures not shown) indicates the same general trend, though not as clearly as during the larger spring freshet of 1997.

These features are related to tidal variations in salinity intrusion and vertical mixing, and the resulting, variable baroclinic contribution to tidal currents. Tidal propagation of salt into the estuary (and the subsequent development of horizontal density gradients) is controlled largely by the mean flow and semidiurnal tides. The diurnal tides render, however, tidal salinity intrusion asymmetric, with maximal asymmetry during peaks in diurnal tidal amplitudes. Consider the North Channel. During high flow periods, am012 is near the head of salinity intrusion. Vessel observations described in Flinchem and Jay (2000) show that salt is totally removed from the vicinity of am012 only on greater ebb. During the weaker ebb, vertical mixing processes are suppressed and there is incomplete removal of salt from the system, leading to strong density stratification and horizontal density gradients near the bottom. Near-bed velocities 
(opposed by the density gradients) are very low on weaker ebb, and there is a pronounced near-bed maximum on the following flood. Thus, diurnal fluctuations in the density field lead to diurnal fluctuations in velocity, and these are maximal near the bed at the leading edge of the salt wedge where horizontal gradients are largest. At am169 in the South Channel, strong, near-bed diurnal currents are seen only during low-moderate flow conditions, because salinity intrusion is minimal during high flows. Strong asymmetry is seen at red26 primarily during high flows, because the salt front is rarely pushed back to red26 under low-moderate flow conditions.

These phenomena can be seen more clearly from the profiles of along-channel velocity on two different days - 19 June 1997 (Figure 12) and 14 November 1997 (Figure 13), when the river discharge are high $\left(\sim 15000 \mathrm{~m}^{3} \mathrm{~s}^{-1}\right)$ and moderate $\left(\sim 5000 \mathrm{~m}^{3} \mathrm{~s}^{-1}\right)$, respectively (see Figure 4$)$. In both figures, snapshots of velocity profiles are plotted for selected ebb and flood times of the two tides during the course of the day, as marked on a tidal time series. On 19 June 1997, we see that the velocity profiles during the strong flood event in Figure 12 are vertically uniform at all the 4 stations, while during the weak flood event the vertical profiles show a maximum near the bottom at all the stations (except am169) due to the strong density gradients generated after the weak ebb. This feature is not observed at am169 because the high river discharge during this period prevents the salt wedge from reaching this station except until just before high water. On 14 November 1997 (Figure 13) on the other hand, the river discharge is around $5000 \mathrm{~m}^{3} \mathrm{~s}^{-1}$, and increased velocities near the bottom during the "weak flood" is clearly discernible at all the stations. Higher velocities at the leading edge of the salt wedge (for the Fraser River) have also been reported by Geyer (1988). Since a significant component of the diurnal velocities are generated by interactions of the tide with a fluctuating density gradient (also referred to as internal tidal asymmetry in Jay and Musiak, 1996), the vertical structure of the tidal currents depend strongly on the location of the leading edge of the salt wedge. Since the salt wedge does not retreat past am169 during low discharge and tidal conditions and rarely past red26 for most weak tidal conditions the maximum velocity amplitudes are closer to the bottom at red26 during the high discharge periods and closer to the bottom at am169 during the low discharge periods. Thus, the interactions between salinity intrusion and river discharge strongly affects the vertical structure of diurnal velocity amplitudes in the South Channel.

To summarize, density gradients play a significant role in for the vertical shear of diurnal tidal currents 
in both the channels. Semidiurnal flows in the North Channel show a nearly barotropic response, but internal tidal asymmetry plays a very dominant role in the generation of diurnal currents. Diurnal velocity amplitudes in the South Channel show a seasonal trend associated with the movement of salt intrusion in response to river flow. The location of the intrusion front influences the local strength of vertical and horizontal density gradients differently at each station, causing time-space diversity and complexity in tidal current patterns. Winds do not seem to have any major discernible role on the velocity amplitudes of the tidal flows other than the retardation due to surface friction.

\section{Conclusions}

The two main channels in the Columbia River estuary have very distinctive dynamics. The South Channel has strong river outflow, moderate tidal currents and a less well-developed salt-wedge. The North Channel has weaker river outflow, more tidal transport, and a more salt-wedge like salinity intrusion. Thus, the two channels constitute, in effect, two rather different sub-estuaries, which increases both the complexity of the Columbia River circulation and the opportunity to observe a variety of dynamical conditions. Analyses of long time-series of moored ADP and CTD data have been carried out to a) characterize the variability in the flow field and corresponding transport processes of the Columbia River estuary under a variety of forcing conditions, b) understand the influence of tidal, fluvial and wind forcing on the low-frequency circulation, and c) define the influence of density forcing on the tidal flow. Our intention was to both provide process understanding and guide the creation of benchmarks for evaluating skill of numerical models. The focus of the analyses was on ADP velocity time-series from four stations; analyses were carried out at the sub tidal (residual) and tidal time scales. Salinity data was used to qualitatively identify the exchange processes between the ocean and the river.

Residual velocities generally show a two-layer pattern with strong neap-spring variability and seasonal variability, the latter primarily due to river flow variations. In addition to seasonal and monthly fluctuations caused by variability in river discharge and tidal ranges, a reduction in residual inflow was also observed during periods of strong alongshore winds to the north. Apparently, downwelling and vertical mixing generated by these winds coupled, with northward movement of the Columbia River plume, reduce the salinity of water flowing into the estuary on flood, which in turn leads to a reduction in the residual inflow. Winds, river flow, and tidal range all influence the position of the landward limit of salt intrusion, and 


\section{A. Chawla et al}

the strongest salinity intrusion occurs, not during periods of greatest tidal ranges, but during periods of highest residual inflow, as influenced by all three factors.

Tidal and subtidal fluctuations in horizontal and vertical density gradients and consequent tidal variations mixing also play a critical role in velocities at the tidal scale. Non-stationarity of the tidal flow has been studied by extracting semidiurnal and diurnal species using continuous wavelet transforms. As expected, peaks in velocity amplitude coincide with peaks in tidal elevation amplitude for both the diurnal and semidiurnal tidal species. The vertical structures of velocity amplitude however show considerable variability. Semidiurnal velocity amplitudes in the South Channel follow the same trends expected of baratropic processes and show limited sensitivity to salt wedge dynamics. In the North Channel however, semidiurnal velocity amplitudes show a variability in their vertical profile and though the exact mechanism for this variability is not clear yet, the salt wedge position is suspected to play a significant role. Diurnal velocities in both the South and North Channel are strongly influenced by salt wedge position, and the South Channel flows show greater variations due to stronger seasonal trends in the moving salt wedge. Thus, there is strong coupling between the residual (which positions the salinity intrusion) and tidal flows in the Columbia River estuary.

The complex seasonal and monthly circulation patterns that we have observed in the data highlight the crucial role played by the tides, river outflow and shelf winds. Table 1 summarizes the response of estuarine circulation to the different forcings. The success of 3D circulation modeling in this system will depend on the ability of circulation models to reproduce these processes. This study also showcases the importance of coastal observatories in understanding the physical processes in a highly dynamic system such as the Columbia River system. A permanent network of observation stations allow us to explore long term variability and at the same time identify interesting events (such as the reduction in salt intrusion due to downwelling) that can then be explored in greater detail.

Acknowledgments We would like to thank Philip M. Orton of Lamont-Doherty Earth Observatory (Columbia University) for plotting the along channel density sections shown in Fig. 1. ADP and CTD data for this project came from CORIE, a prototype coastal-margin ocean observing system for the Columbia River and adjacent coast. We are grateful to the Bonneville Power Administration, National Oceanic and 
Atmospheric Administration, U.S. Geological Survey and U.S. Army Corps of Engineers for providing additional data. The National Oceanic and Atmospheric Administration (NA17FE1026, NA87FE0405), the U.S. Fish and Wildlife Service (133101J104) and the National Science Foundation (NSF) (ACl-0121475) provided financial support for this research and for the development of CORIE. The NSF Coastal Ocean Program funded RISE (River-Influenced Shelf Ecosystems) Program provided support for participation of DAJ.

\section{References}

Burla M., A.M. Baptista, E. Casillas, J.G. Williams. "The influence of the Columbia River plume on the survival of steelhead (Oncorhynchus mykiss) and chinook salmon (O. tshawytscha): a numerical exploration," submitted December 2006 to Canadian Journal of Fisheries and Aquatic Sciences

Baptista A.M. (2006). "CORIE: the first decade of a coastal-margin collaborative observatory," Oceans'06, MTS/ IEEE, Boston, MA

Baptista, A. M., Wilkin, M., Pearson, P., Turner, P., McCandlish C. and Barrett, P. (1999). Coastal and estuarine forecast systems - A multi-purpose infrastructure for the Columbia River. Earth System Monitor, 9(3).

Baptista, A. M., Zhang, Y., Chawla, A., Zulauf, M., Seaton, C., Myers E. P. III, Kindle, J., Wilkin, M., Burla, M., and Turner, P. J. (2005) "A cross-scale model for 3D baroclinic circulation in estuary-plume-shelf systems: II. Application to the Columbia River", Continental Shelf Research, 25, 935 - 972.

Bottom, D. L., C. A. Simenstad, J. Burke, A. M. Baptista, D. A. Jay, K. K. Jones, E. Casillas, M. H. Schiewe. 2005. Salmon at river's end: The role of the estuary in the decline and recovery of Columbia River salmon. U.S. Dept. of Commerce, NOAA Tech. Memo., NMFS-NWFSC-68, $246 \mathrm{p}$ (final report).

Davies, A. M. (1990). On the importance of time varying eddy viscosity in generating higher tidal harmonics. Journal of Geophysical Research, 95(C11), 20287-20312.

Davies, A. M. (1993). Numerical problems in simulating tidal flows with a frictional-velocitydependent eddy viscosity and the influence of stratification. International Journal for numerical methods in fluids, 16, 105-131.

Emery, W. J. and Thomson, R. E. (2001). Data Analysis Methods in Physical Oceanography, chapter Wavelet Analysis, pages 501-505. Elsevier, second edition.

Fain, A.M.V., D. A. Jay, D. J. Wilson, P. M. Orton, and A. M. Baptista, 2001, Seasonal, monthly and tidal patterns of particulate matter dynamics in the Columbia River estuary, Estuaries 24: 770-786.

Flinchem, E. and Jay, D. (2000). An introduction to wavelet transform tidal analysis methods. Estuarine, Coastal and Shelf Science, 51, 177-200.

Geyer, W. R. (1988). The advance of a salt wedge: observations and dynamical model. In J. Dronkers and W. van Leussen, editors, Physical Processes in Estuaries, pages 181195. Springer-Verlag, New York.

Haidvogel, D., Arango, H. G., Hedstrom, K., Beckmann, A., Malanotte - Rizzoli, P. and Shchepetkin, A. F. (2000). Model evaluation experiments in the north atlantic basin : simulations in non-linear terrain - following coordinates. Dynamics of Atmosphere and Oceans, 32, 239-281. 
Hansen, D. V. and Rattray, M. J. (1965). Gravitational circulation in straits and estuaries. Journal of Marine Res., 23, 104-122.

lanniello, J. P. (1977). Tidally induced residual currents in estuaries of constant breadth and depth. Journal of Marine Res., 35(4), 755-786.

Jay, D. A. and Flinchem, E. P. (1997). Interaction of fluctuating river flow with a barotropic tide: A demonstration of wavelet tidal analysis methods. Journal of Geophysical Research, 102(C3), 5705-5720.

Jay, D. A. (1984), Circulatory processes in the Columbia River Estuary, CREST, Astoria, Oregon, 169 pp. plus appendices.

Jay, D. A. and Flinchem, E. P. (1999). A comparison of methods for analysis of tidal records containing multi-scale non-tidal background energy. Continental Shelf Research, 19, 1695-1732.

Jay, D. A. and Musiak, J. D. (1996). Internal tide asymmetry. In C. B. Pattiaratchi, editor, Mixing in Estuaries and Coastal Seas, Coastal and Estuarine Studies, pages 211-249. American Geophysical Union, Washington D.C.

Jay, D. A. and Smith, J.D. (1990a). Circulation, density distribution and neap-spring transitions in the Columbia River estuary. Progress in Oceanography, 25, 81-112.

Jay, D. A. and Smith, J. D. (1990b). Residual circulation in shallow estuaries:I. highly stratified, narrow estuaries. Journal of Geophysical Research, 95, 711-731.

Jay, D. A. and Smith, J. D. (1990c). Residual circulation in shallow estuaries:2. Weakly stratified and partially mixed, narrow estuaries. Journal of Geophysical Research, 95, 733-748.

Kay, D. J., D. A. Jay and Musiak, J. D. (1996). Salt transport through an estuarine crosssection calculated from moving vessel ADCP and CTD data Buoyancy Effects on Coastal and Estuarine Dynamics, AGU Coastal and Estuarine Studies 53:195-212.

Kay, D. J. and Jay, D.A. (2003). Interfacial mixing in a highly stratified estuary 2. A "method of constrained differences" approach for the determination of the momentum and mass balances and the energy of mixing. Journal of Geophysical Research, 108(C3),18-1 18-11.

Kukulka, T., and D. A. Jay, 2003a, Impacts of Columbia River discharge on salmonid habitat I. a non-stationary fluvial tide model, J. Geophys. Res. 108, 3293 doi 10.1029/2002JC001382.

Li, C. and O'Donnell, J. (1997). Tidally driven residual circulation in shallow estuaries with lateral depth variation. Journal of Geophysical Research, 102(C13), 27915-27929.

McCarthy, R. K. (1993). Residual currents in tidally dominated, well-mixed estuaries. Tellus, 45A, 325-340.

Meyers, S. D., Kelley, B. G. and O'Brien, J. J. (1993). An introduction to wavelet analysis in oceanography and meteorology: With application to the dispersion of the yanai waves. Monthly Weather Review, 121, 2858-2866.

Monismith, S. G. and Fong, D. A. (1996). A simple model of mixing in stratified tidal flows. Journal of Geophysical Research, 101, 28583 - 28597.

Panizzo, A., Bellotti, G., and Girolamo, P. D. (2002). Application of wavelet transform analysis to landslide generated waves. Coastal Engineering, 44, 321-338.

Shen, Z., Wang, W. and Mei, L. (1994). Fine structure of wind waves analyzed with wavelet transforms. Journal of Physical Oceanography, 24, 1085-1094.

Sherwood, C., Jay, D., Harvey, R., Hamilton, P. and Simenstad, C. (1990). Historical changes in the columbia river estuary. Progress in Oceanography, 25, 299-352. 

A. Chawla et al

Simpson, J. H., Brown, J., Matthews, J. and Allen, G. (1990). Tidal straining, density currents and stirring in the control of estuarine stratification. Estuaries, 13(2), 125-132.

Sontex (1997). SonTex ADP Acoustic Doppler Profiler Technical Manual. SONTEX, San Diego CA. version 4.4 .

Uncles, R. J. and Stephens, J.A. (1990). The structure of vertical current profiles in a macro tidal, partly-mixed estuary. Estuaries, 13(4), 349-361.

Zhang, Y.-L., Baptista, A. and E. P. Myers III (2004). A cross-scale model for 3D baroclinic circulation in estuary-plume-shelf systems: I. formulation and skill assessment. Continental Shelf Research, 24, 2187 - 2214. 
Table 1: Summary of the influence of external forcings on circulation dynamics at various scales inside the Columbia River estuary

\begin{tabular}{|c|c|c|c|}
\hline & External Forcing & & \\
\hline Scale & Shelf Winds & Discharge & Tides \\
\hline Residual circulation & $\begin{array}{l}\text { Sporadically important } \\
\text { through the combined } \\
\text { effect of downwelling } \\
\text { and plume transport } \\
\text { during winter storms } \\
\text { when the winds are in } \\
\text { the N-S direction and } \\
\text { through a barotropic } \\
\text { and baroclinic } \\
\text { adjustment process } \\
\text { when the winds are in } \\
\text { the E-W direction }\end{array}$ & $\begin{array}{l}\text { A dominant seasonal } \\
\text { influence (due to spring } \\
\text { freshets) }\end{array}$ & $\begin{array}{l}\text { A dominant neap } \\
\text { spring influence (due } \\
\text { to tidal asymmetry) }\end{array}$ \\
\hline $\begin{array}{l}\text { Semidiurnal } \\
\text { circulation }\end{array}$ & Negligible influence & $\begin{array}{l}\text { Modest influence due } \\
\text { to frictional bedstress } \\
\text { interactions }\end{array}$ & $\begin{array}{c}\text { A dominant } \\
\text { barotropic influence, } \\
\text { with a weak } \\
\text { baroclinic influence of } \\
\text { tidal asymmetry in } \\
\text { the North Channel }\end{array}$ \\
\hline Diurnal circulation & Negligible influence & $\begin{array}{l}\text { A moderate influence in } \\
\text { the South Channel } \\
\text { (due to impact of } \\
\text { moving salt wedge on } \\
\text { tidal asymmetry) }\end{array}$ & $\begin{array}{l}\text { A dominant baroclinic } \\
\text { influence (tidal } \\
\text { asymmetry) }\end{array}$ \\
\hline
\end{tabular}


Table 2: Summary of CORIE data used in the development of process based benchmarks

\begin{tabular}{|c|c|c|c|}
\hline Station ID & Instrument type & Data type & Period covered (m/d/y) \\
\hline \multirow{2}{*}{ am012 } & \multirow{2}{*}{ ADP } & \multirow{2}{*}{ Velocity } & $05 / 22 / 1997-11 / 30 / 1997$ \\
\cline { 3 - 4 } & ADP & Velocity & $07 / 28 / 2001-04 / 23 / 2002$ \\
\hline am169 & ADP & Velocity & $03 / 25 / 1997-11 / 30 / 1997$ \\
\hline tansy & ADP & Velocity & $04 / 21 / 1997-11 / 30 / 1997$ \\
\hline \multirow{2}{*}{ red26 } & CTD & Salinity & $10 / 30 / 2001-05 / 16 / 2002$ \\
\hline sandi & CTD & Salinity & $10 / 30 / 2001-05 / 16 / 2002$ \\
\hline eliot & CTD & Salinity & $08 / 31 / 2001-03 / 10 / 2004$ \\
\hline ogi01 & CTD & Salinity & $08 / 31 / 2001-12 / 14 / 2002$ \\
\hline
\end{tabular}




\section{Figure Captions}

Fig. 1: Salinity intrusion (developed from vessel CTD cast data) in the South Channel of the Columbia River estuary (see map in Fig 2) during two very different spring freshet periods, 1997 and 2001. These correspond to the highest and lowest spring freshets respectively, of the last decade. Salt intrusion doubles with a decrease in river flow by a factor of four; distance is measured along the South Channel from the mouth of the estuary.

Fig. 2: Columbia River estuary shoreline and bathymetry; depth is indicated by color. A subset of CORIE observation stations (indicated by white squares in inset figure) are shown. Those stations used in this analysis have been labeled. Also shown are the NOAA buoy 46029 (for offshore wind conditions) and NOAA tidal station at Tongue Point (Astoria).

Fig. 3: Along channel residual velocities (in $\mathrm{ms}^{-1}$ ) as a function of time and depth for the four ADP stations during 1997. Positive velocities are landward. The vertical axis $(z)$ is positive upward and refers to the distance (in $\mathrm{m}$ ) from the mean sea level (MSL).

Fig. 4: Time series of dimensionless Inflow Number for the four ADP stations, daily tidal range (NOAA tidal gage), daily averaged along and onshore winds (NOAA buoy; +ve values refer to winds blowing from the south and west respectively) and daily averaged river discharge (Bonneville dam).

Fig. 5: Inflow Number vs River Discharge for the four ADP stations. The North channel station (am012) shows consistently a double layer flow. For the South channel stations, a transition occurs around river discharge $8,000 \mathrm{~m}^{3} \mathrm{~s}^{-1}$, above which no two layer pattern develops.

Fig. 6: Inflow Number vs Tidal Range for ADP data between July and August in Fig. 4. 'Black' corresponds to actual data and 'Red' corresponds to curve fitting.

Fig. 7: Time series of daily maximum salinity at two estuarine stations (sandi; instrument depth $=7.9 \mathrm{~m}$ and red26; instrument depth=9m), daily minimum salinity at ogi01 (instrument depth=1m), the depth 


\section{A. Chawla et al}

integrated residual inflow (at am012), the daily tidal range, the daily averaged alongshore wind (positive values refer to downwelling conditions), the sub tidal elevation, and the daily river flow. Time is in months for the years 2001/2002.

Fig. 8: Time series of daily maximum salinity (eliot; instrument depth=13.6 m), daily minimum salinity (ogi01; instrument depth=1m) along with tidal range, alongshore and onshore wind components, sub-tidal elevation and river discharge. Time is in MM/YY format and the time series extends from September 2001 through March 2004.

Fig. 9: Semidiurnal tidal velocity amplitude (in $\mathrm{ms}^{-1}$ ) as a function of depth and time at all four ADP stations. The period of time covered is the same as in Figures 3 and 4 . Also shown are time series of semidiurnal tidal elevation amplitude (in $\mathrm{m}$ ), and the daily averaged winds and river discharge.

Fig. 10: Scatter plots of maximum (over depth) semidiurnal velocity amplitude (y-axis) vs semidiurnal tidal elevation amplitude (x-axis) at the four ADP stations. Goodness of fit parameter $\left(r^{2}\right)$ as well as the slope (m) and intercept (c) are also shown.

Fig. 11: Diurnal tidal velocity amplitude (in $\mathrm{ms}^{-1}$ ) as a function of depth and time at the four ADP stations. Also shown are time series of diurnal tidal elevation amplitude (in $\mathrm{m}$ ) and the daily averaged winds and river discharge.

Fig. 12: Alongchannel velocity profiles at the four ADP stations for two tidal periods on 06/19/1997; river flow is $\sim 15000 \mathrm{~m}^{3} \mathrm{~s}^{-1}$ (see Fig. 4). Instances of vertical profiles are marked on a tidal time series. For clarity, within each plot individual, profiles are separated by an additional increment of $0.15 \mathrm{~ms}^{-1}$.

Fig. 13: Snapshots of along channel velocity profile at the 4 ADP stations for two tidal periods on 11/14/1997. The river discharge during this time is $\sim 5000 \mathrm{~m}^{3} \mathrm{~s}^{-1}$; details as in Fig. 12. 


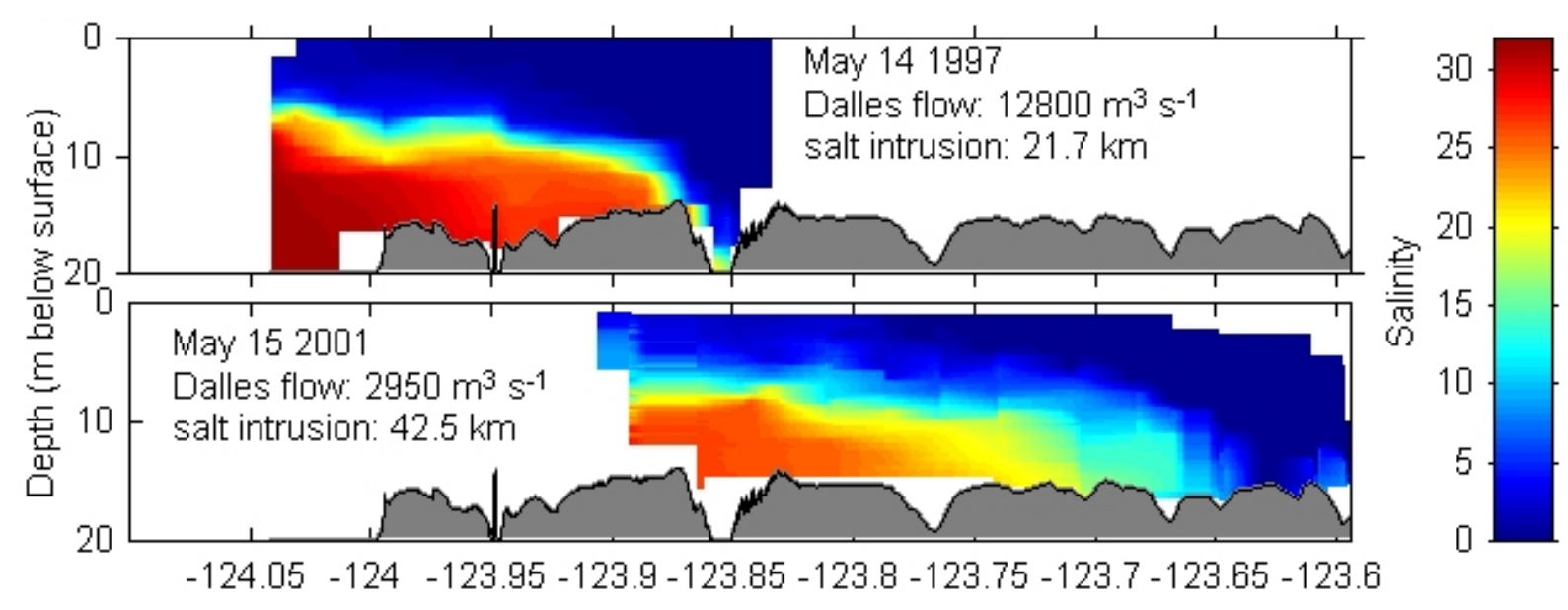

Figure 1 


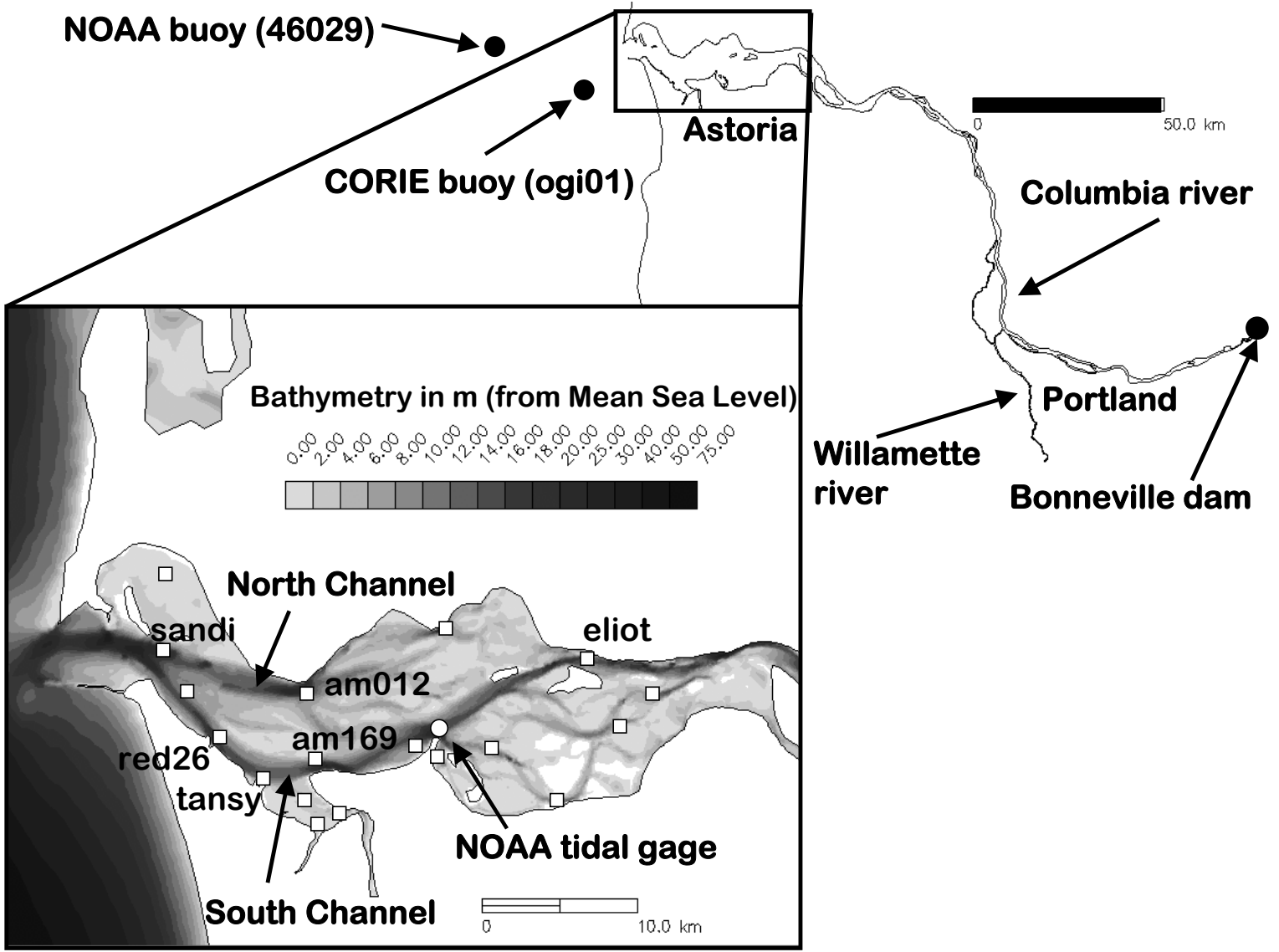

Figure 2 

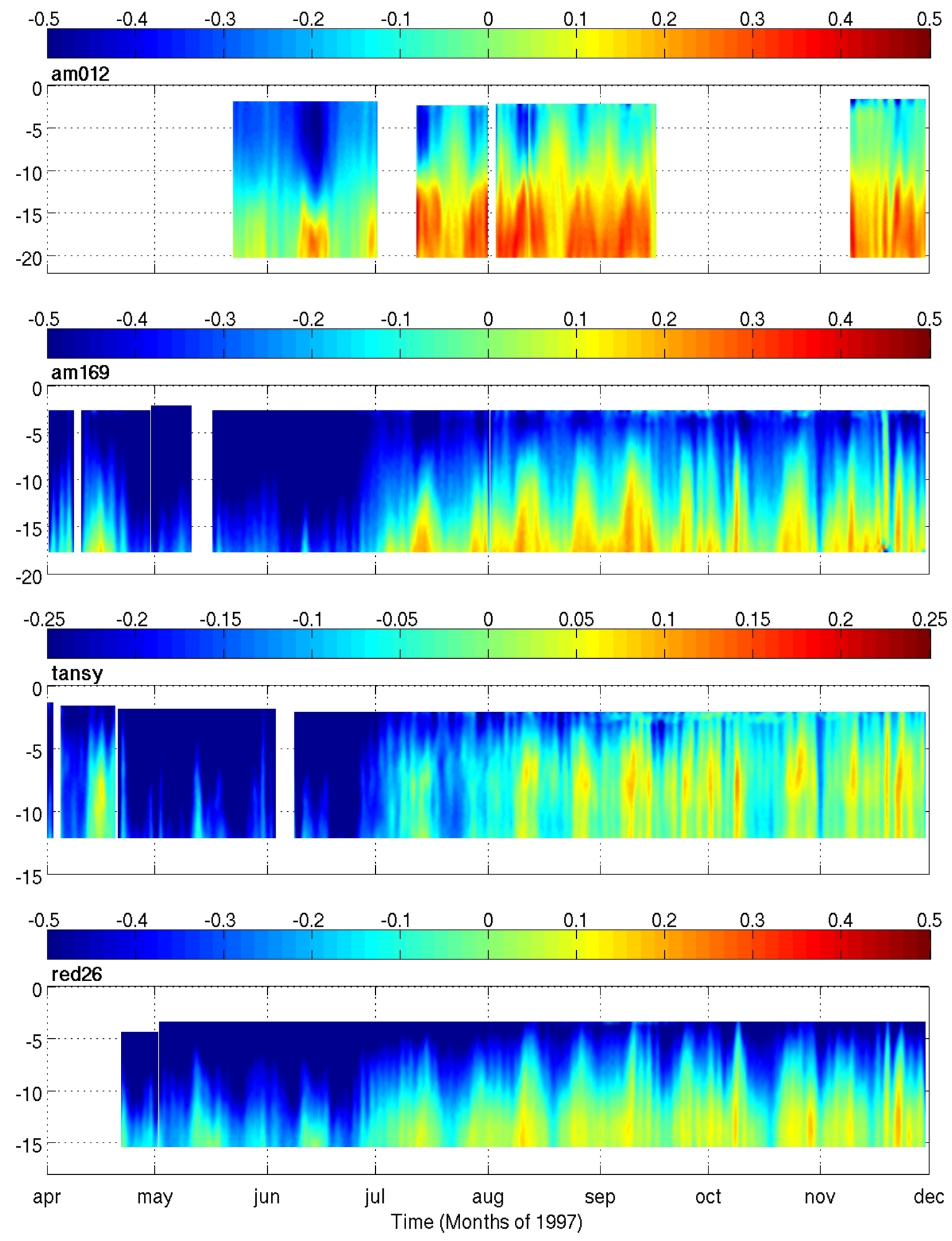

Figure 3 

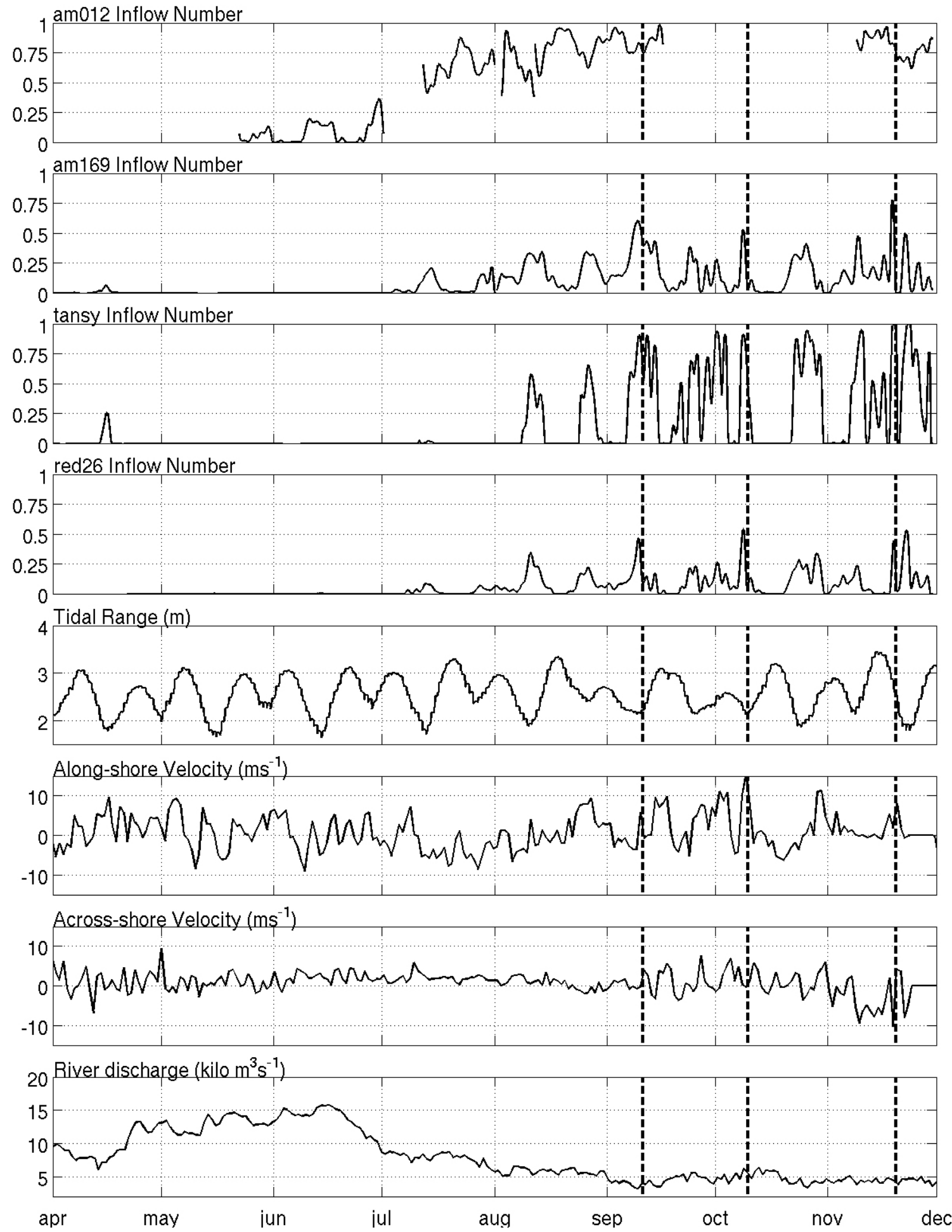

Figure 4 
A. Chawla et al
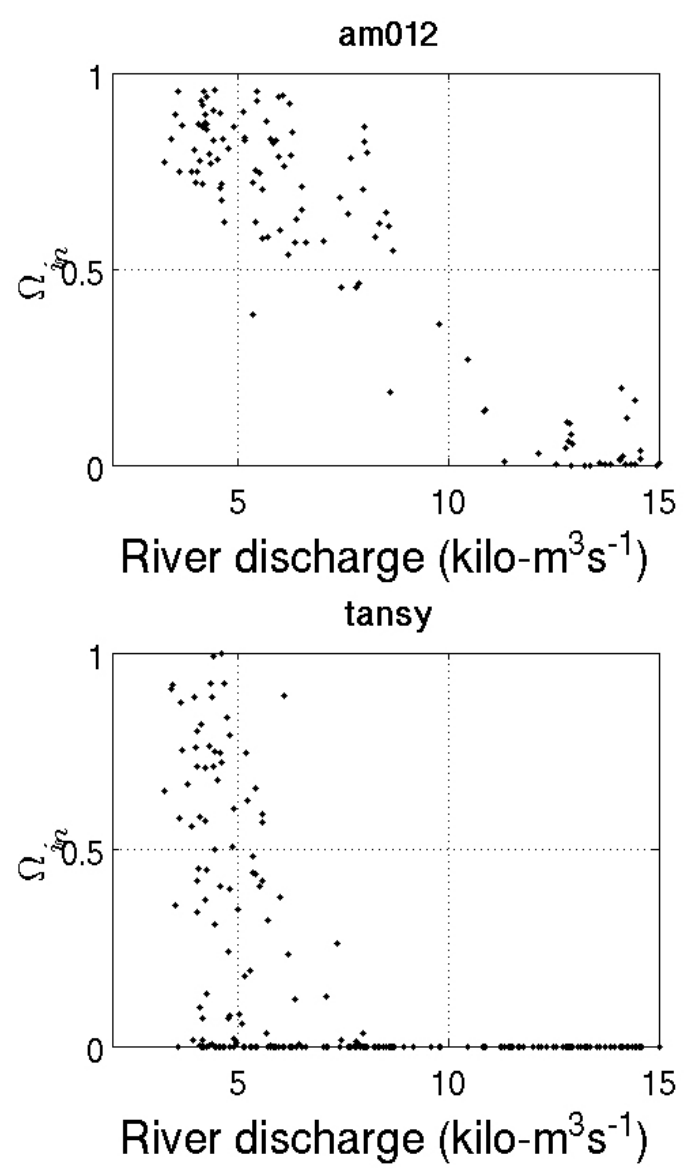

Circulation in a river dominated estuary
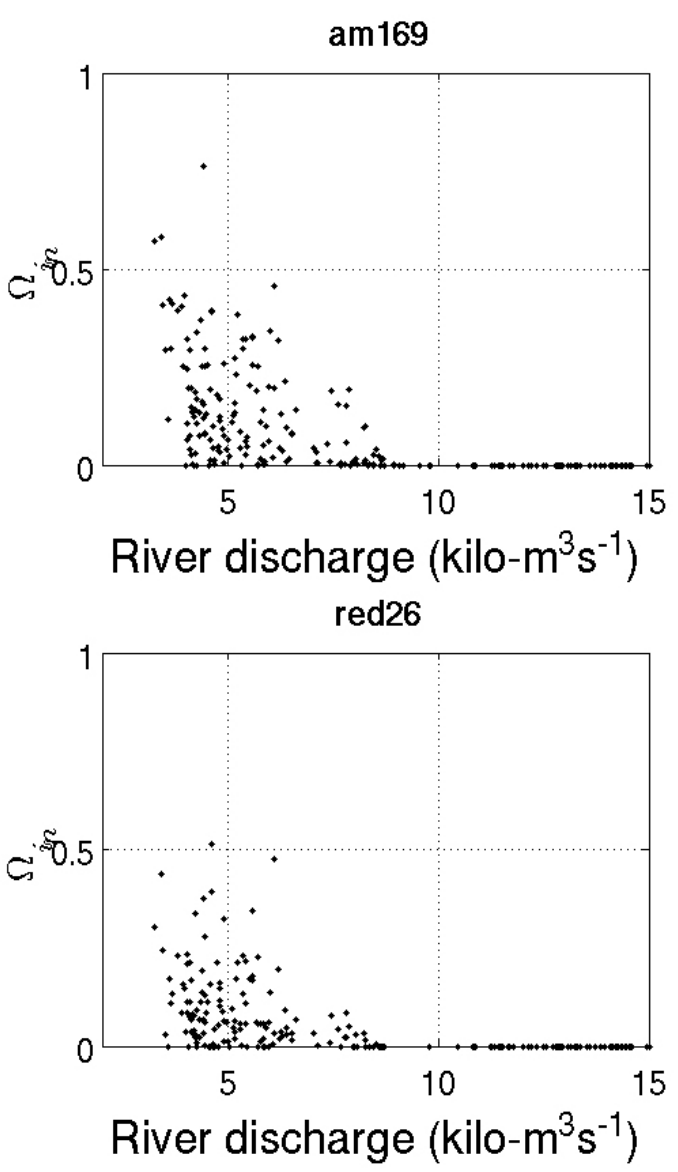

Figure 5 

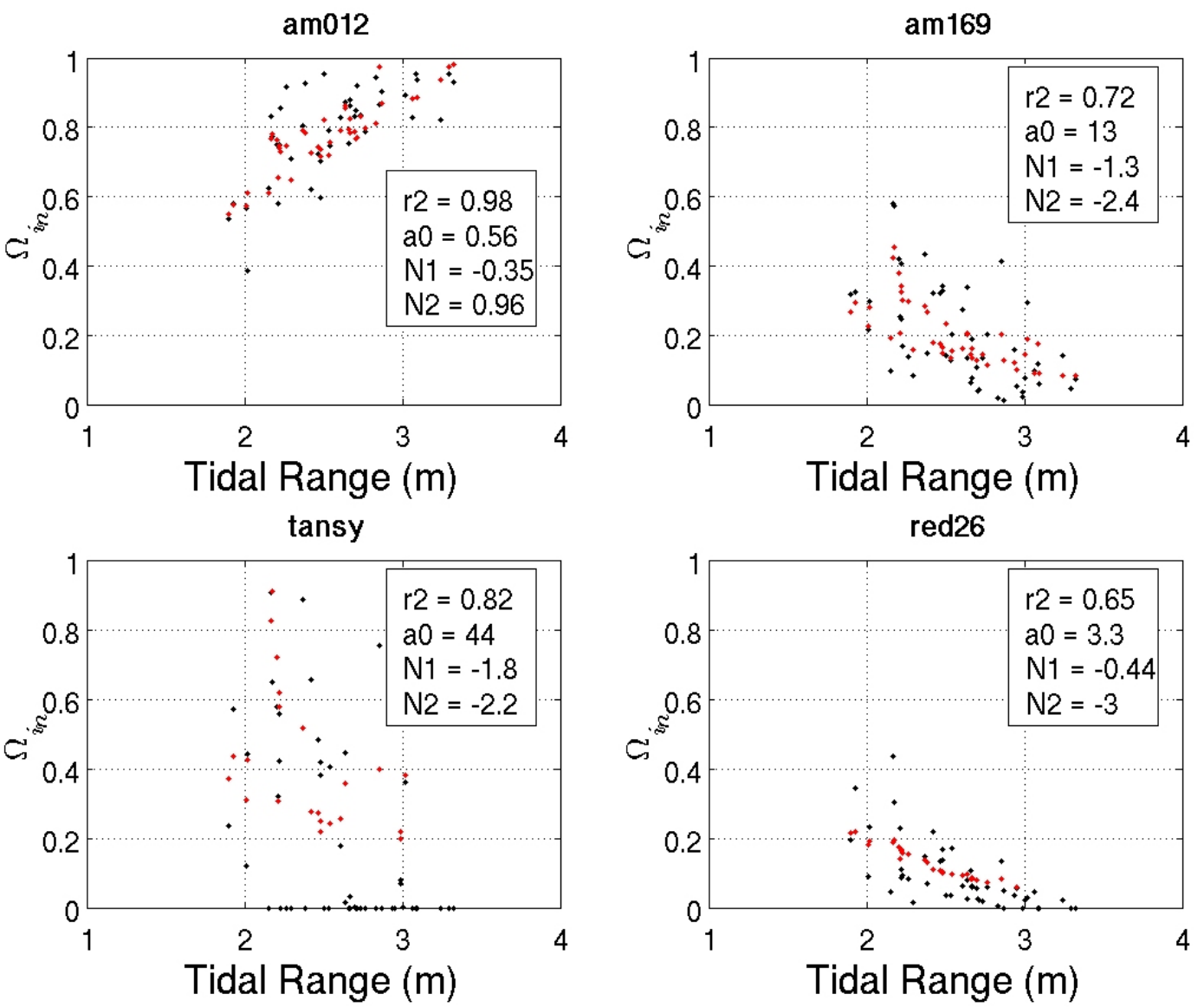

Figure 6 

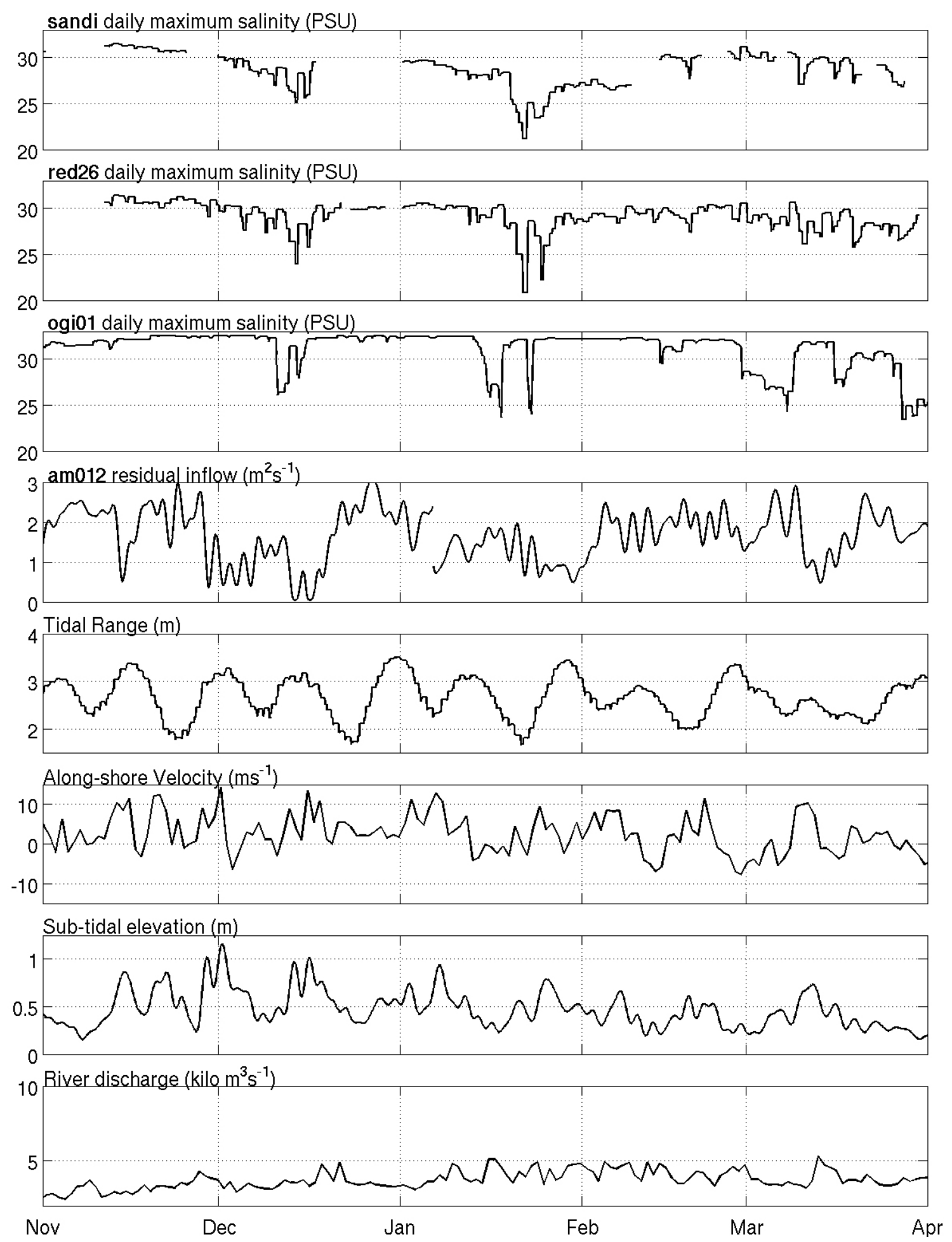

Figure 7 

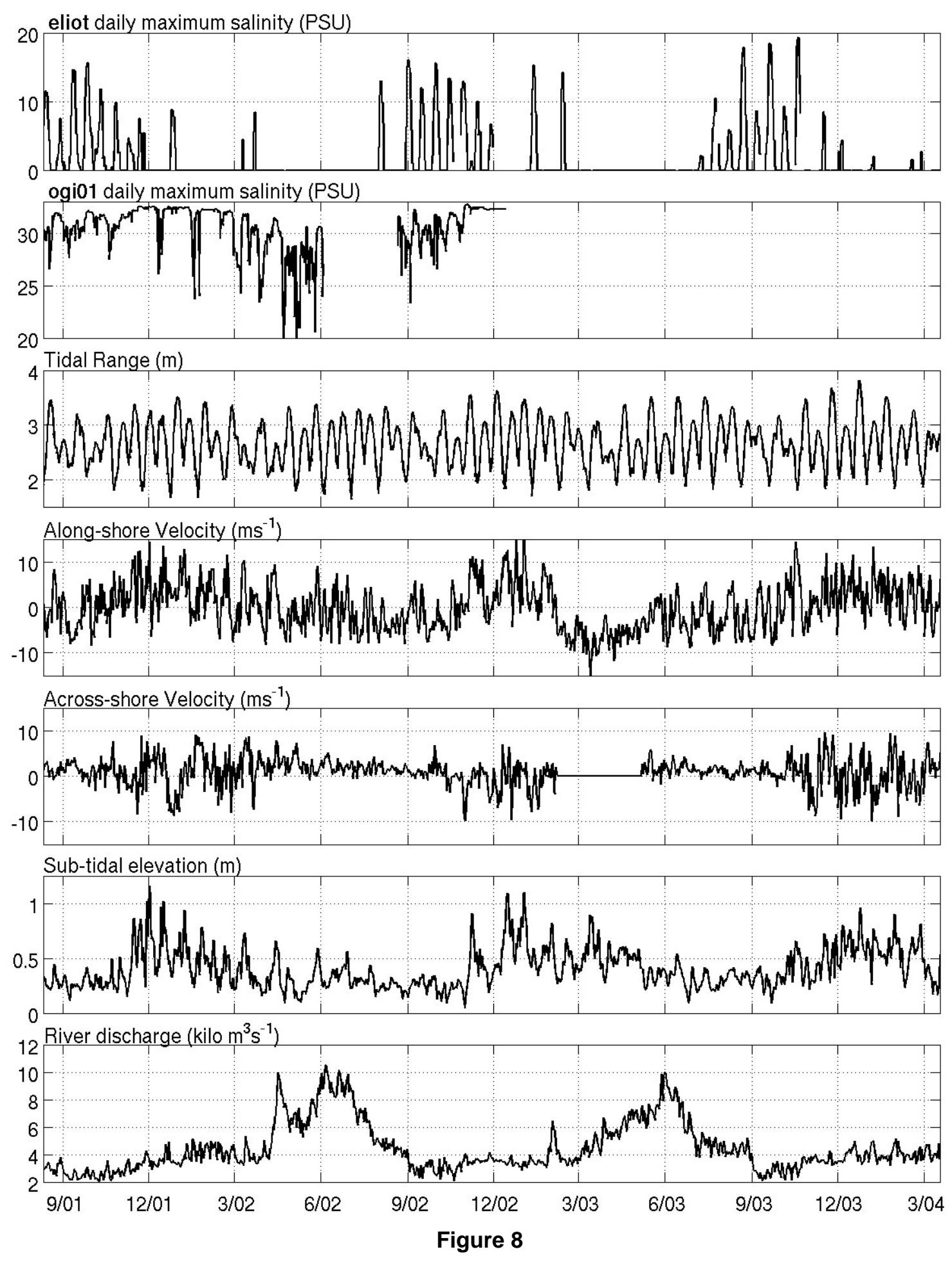


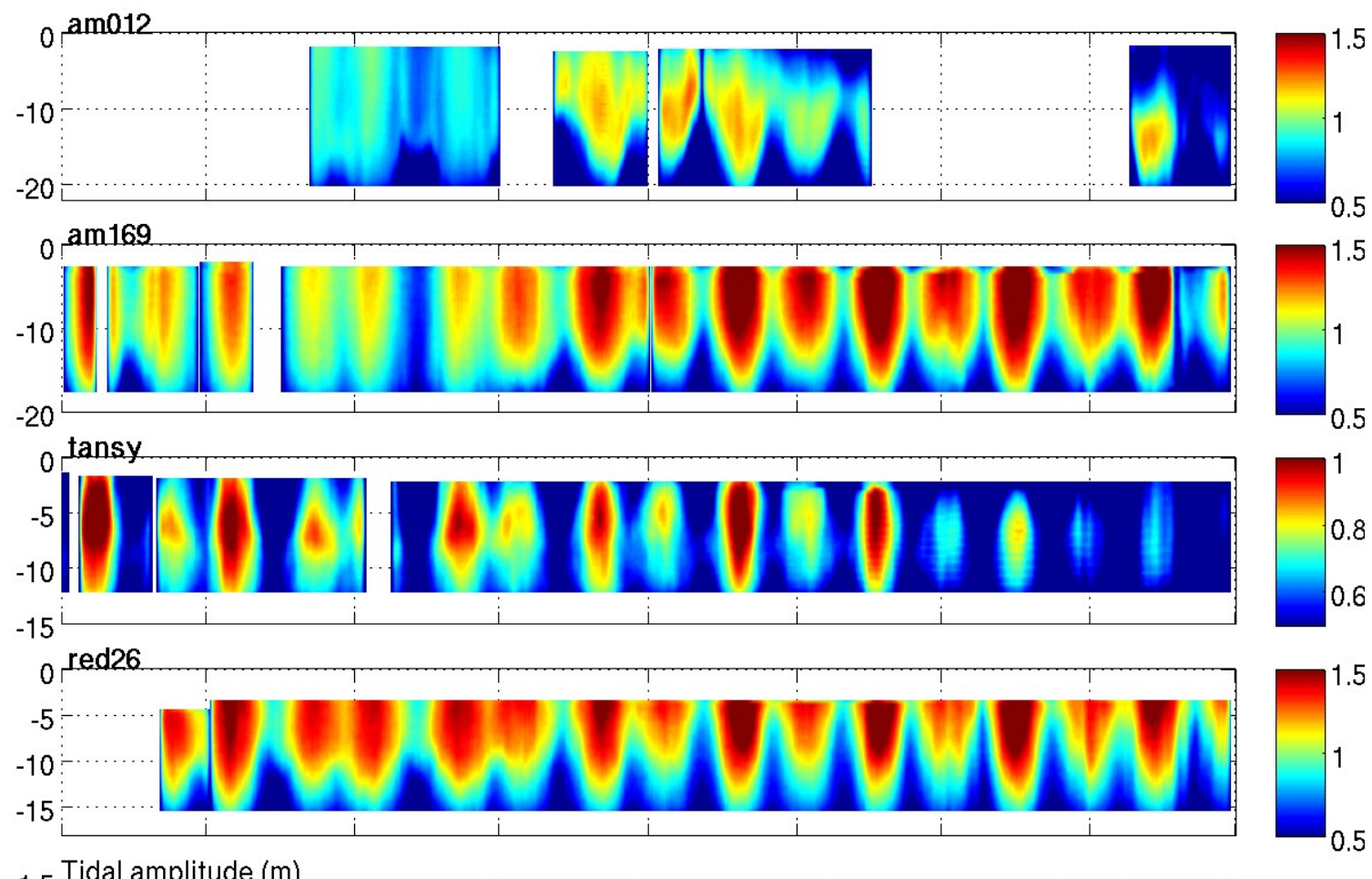

1.5 Tidal amplitude $(\mathrm{m})$

Along-shore Velocity $\left(\mathrm{ms}^{-1}\right)$

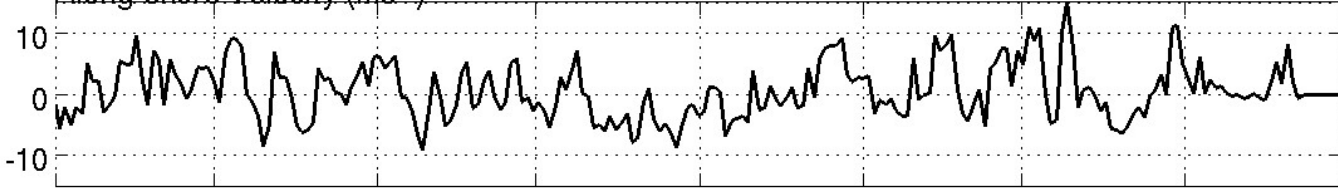

Across-shore Velocity $\left(\mathrm{ms}^{-1}\right)$

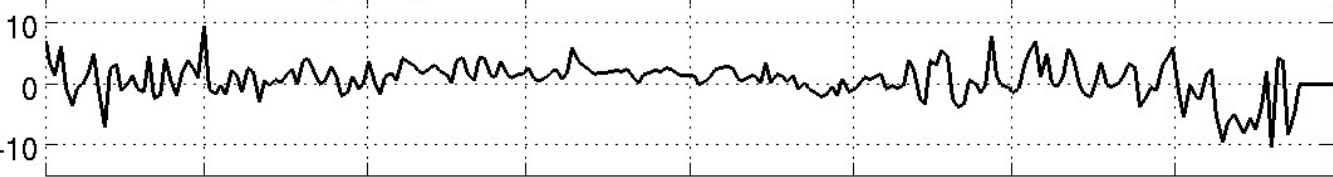

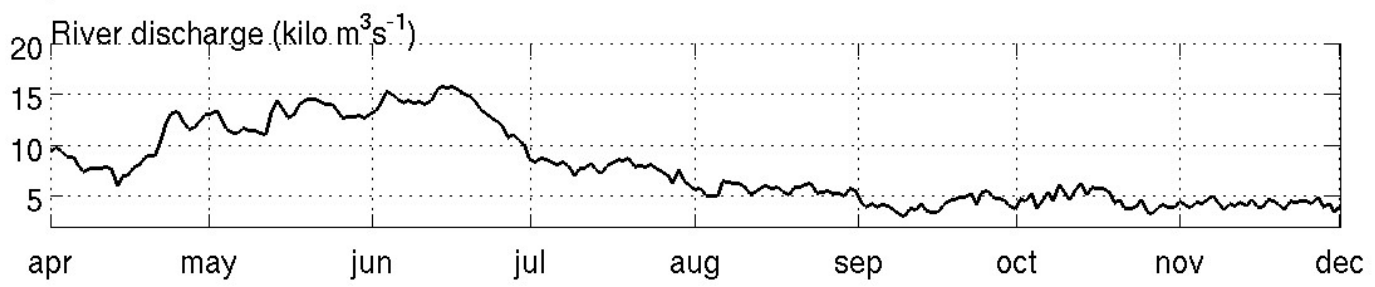

Figure 9 

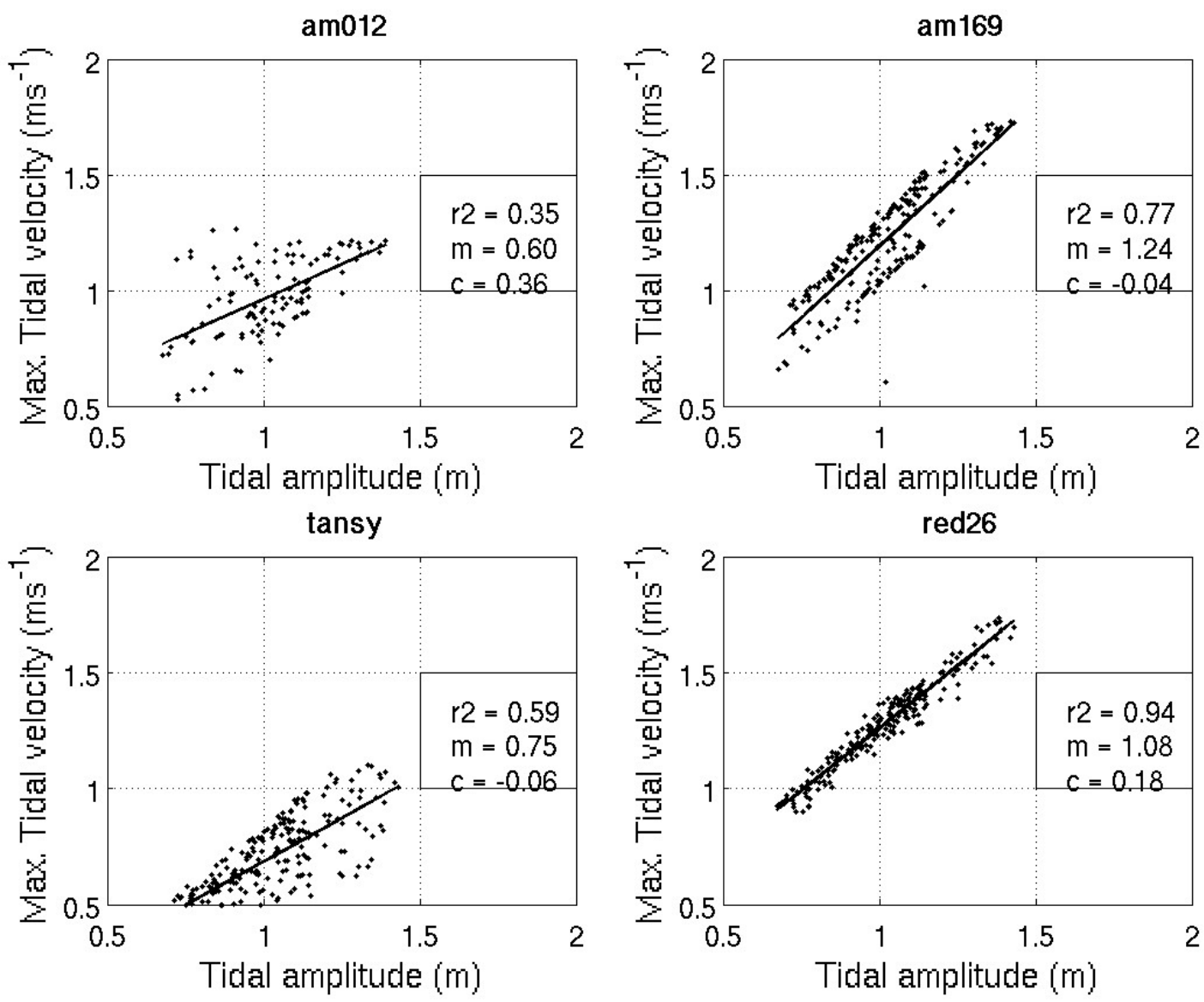

Figure 10 


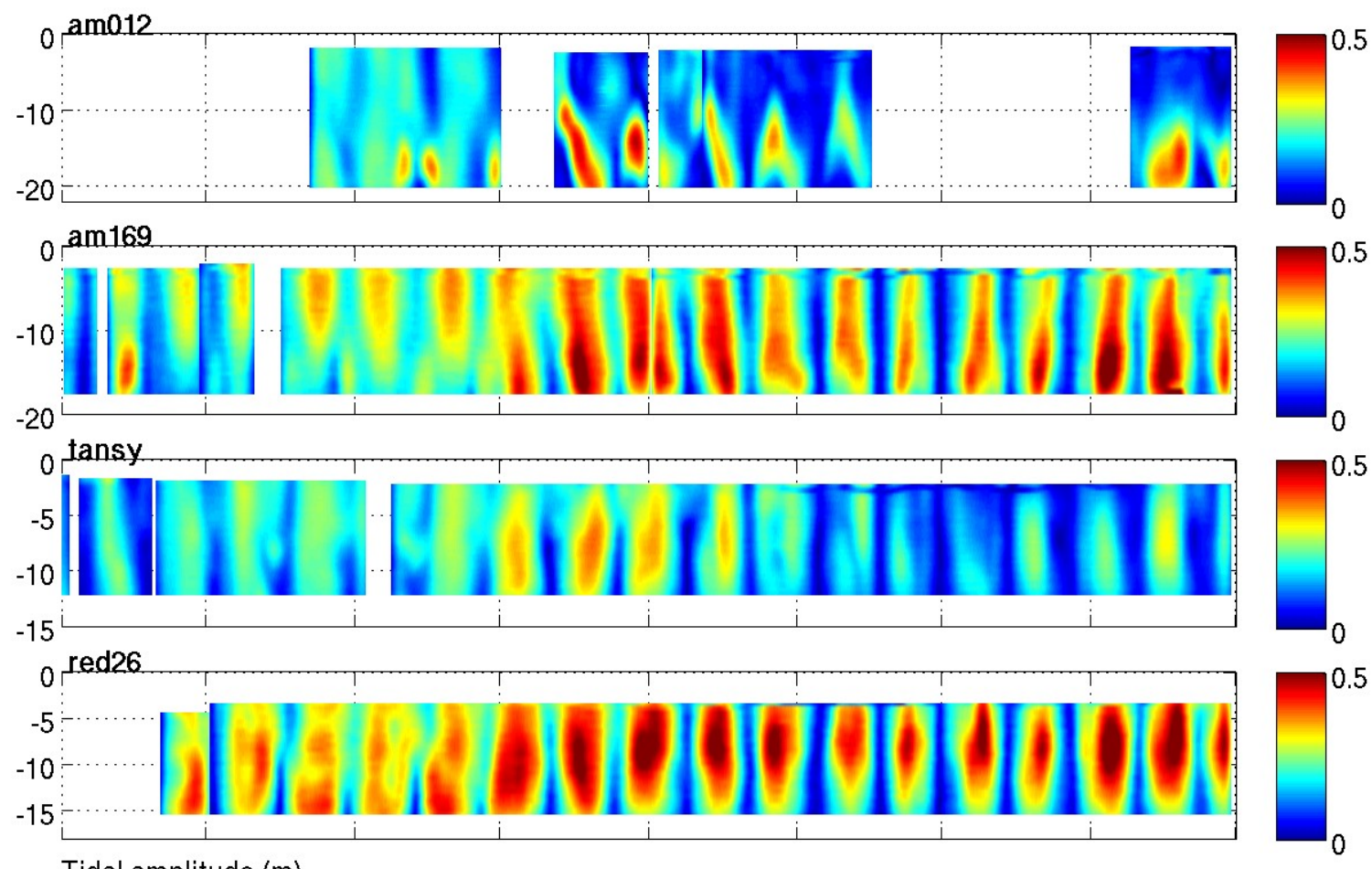

Tidal amplitude (m)

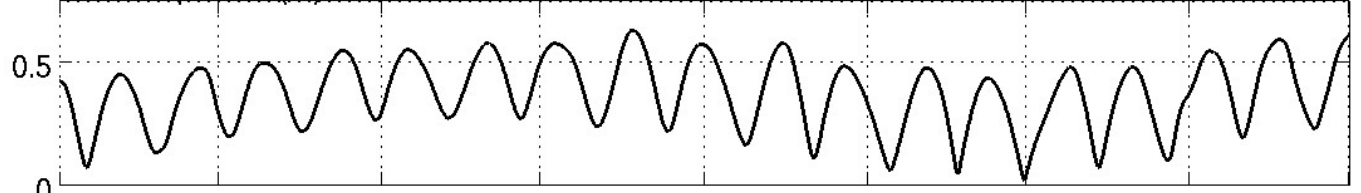

Along-shore Velocity $\left(\mathrm{ms}^{-1}\right)$

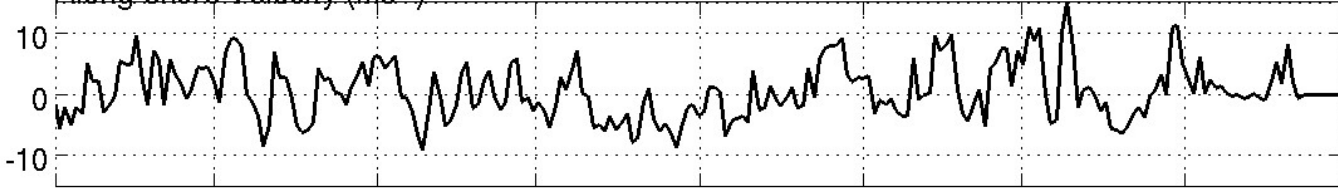

Across-shore Velocity $\left(\mathrm{ms}^{-1}\right)$

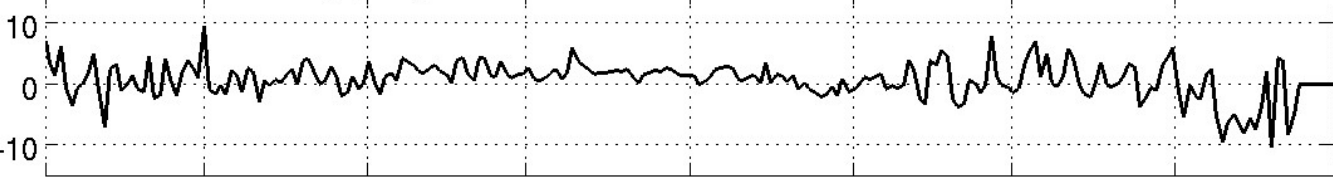

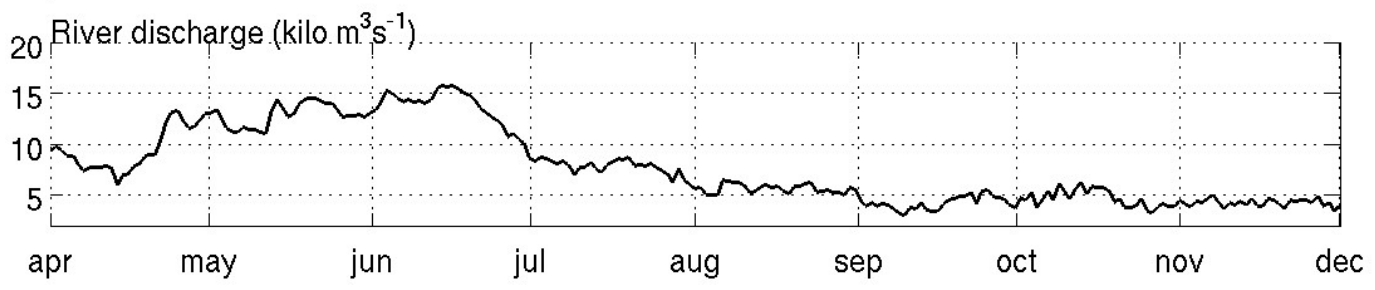

Figure 11 
Tidal time series on 6/19/97
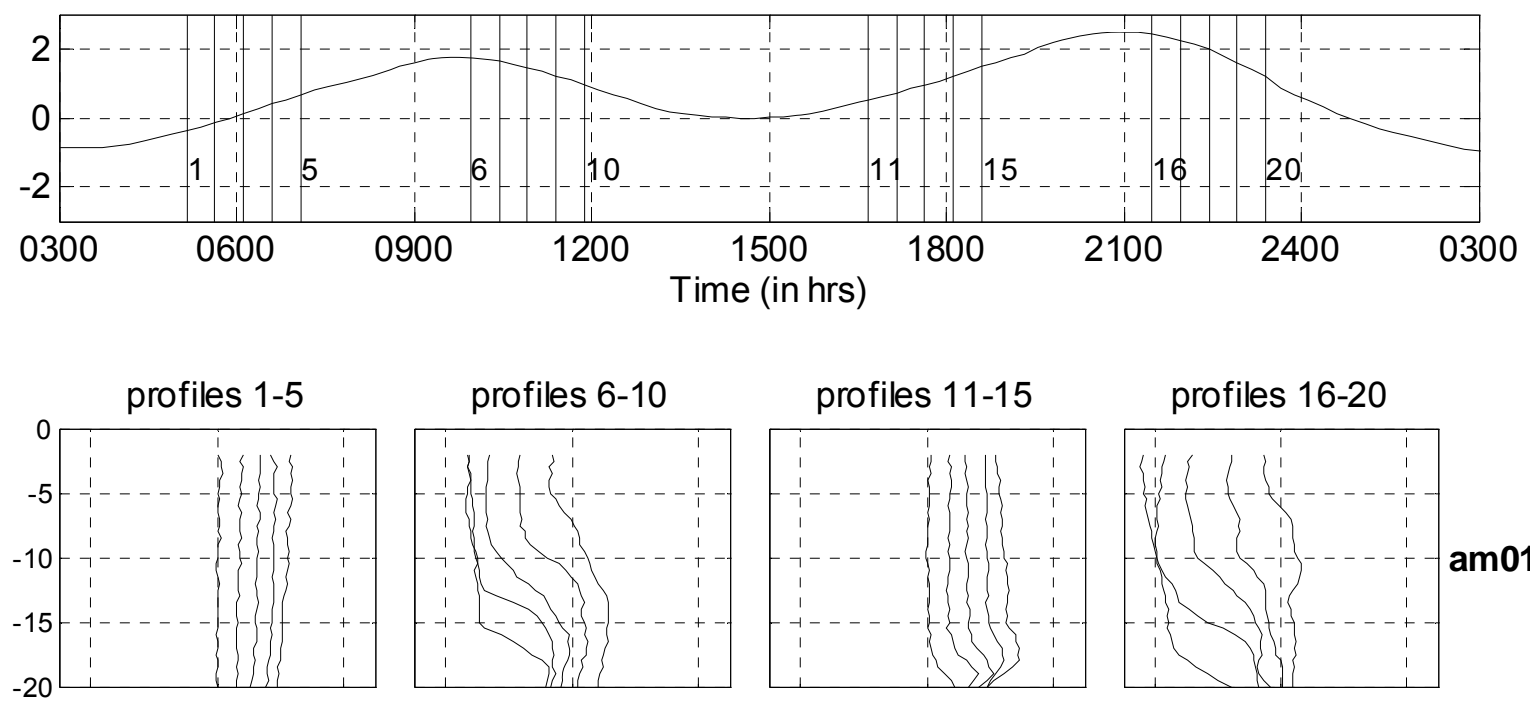

profiles $16-20$
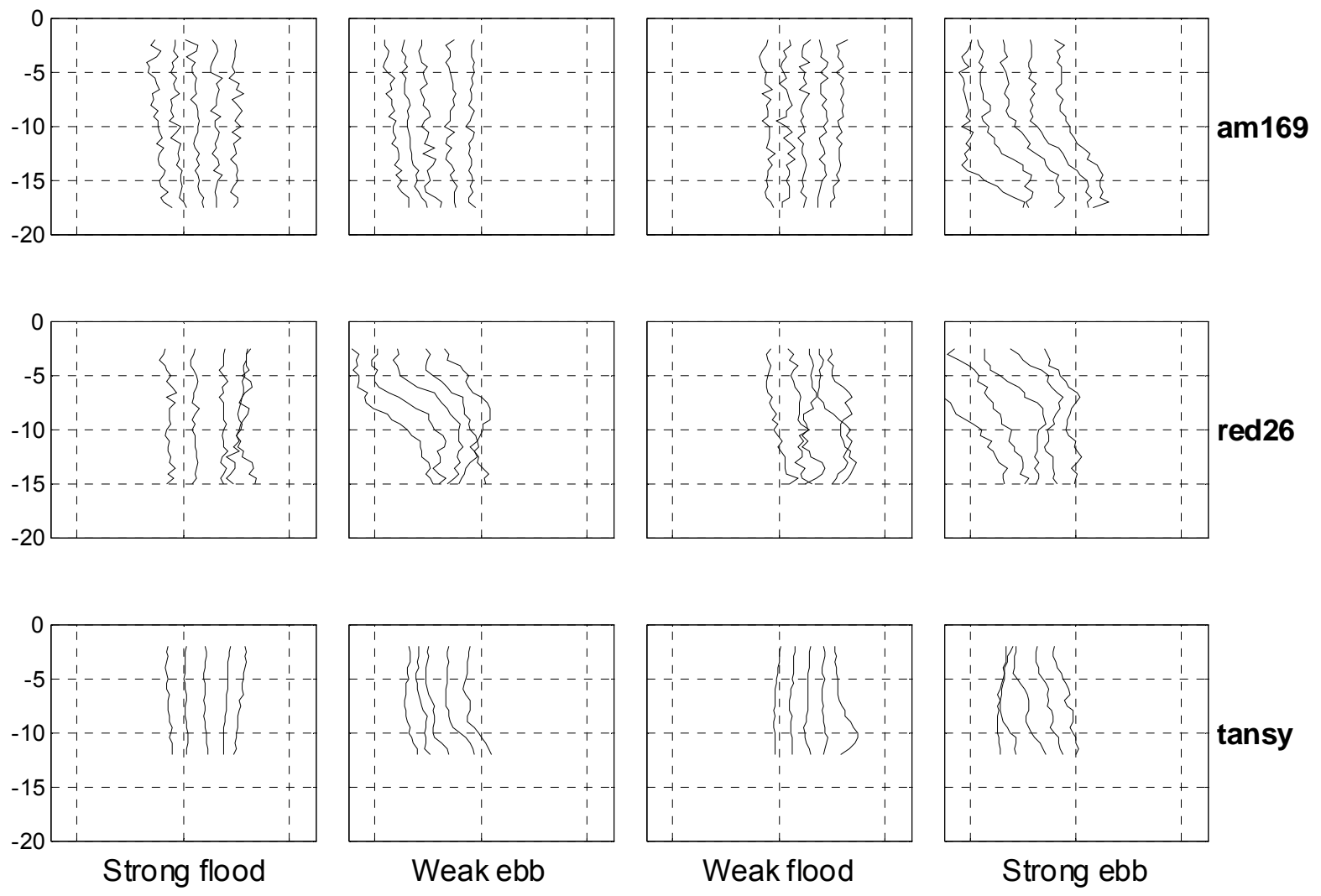

Figure 12 
Tidal time series on 11/14/97
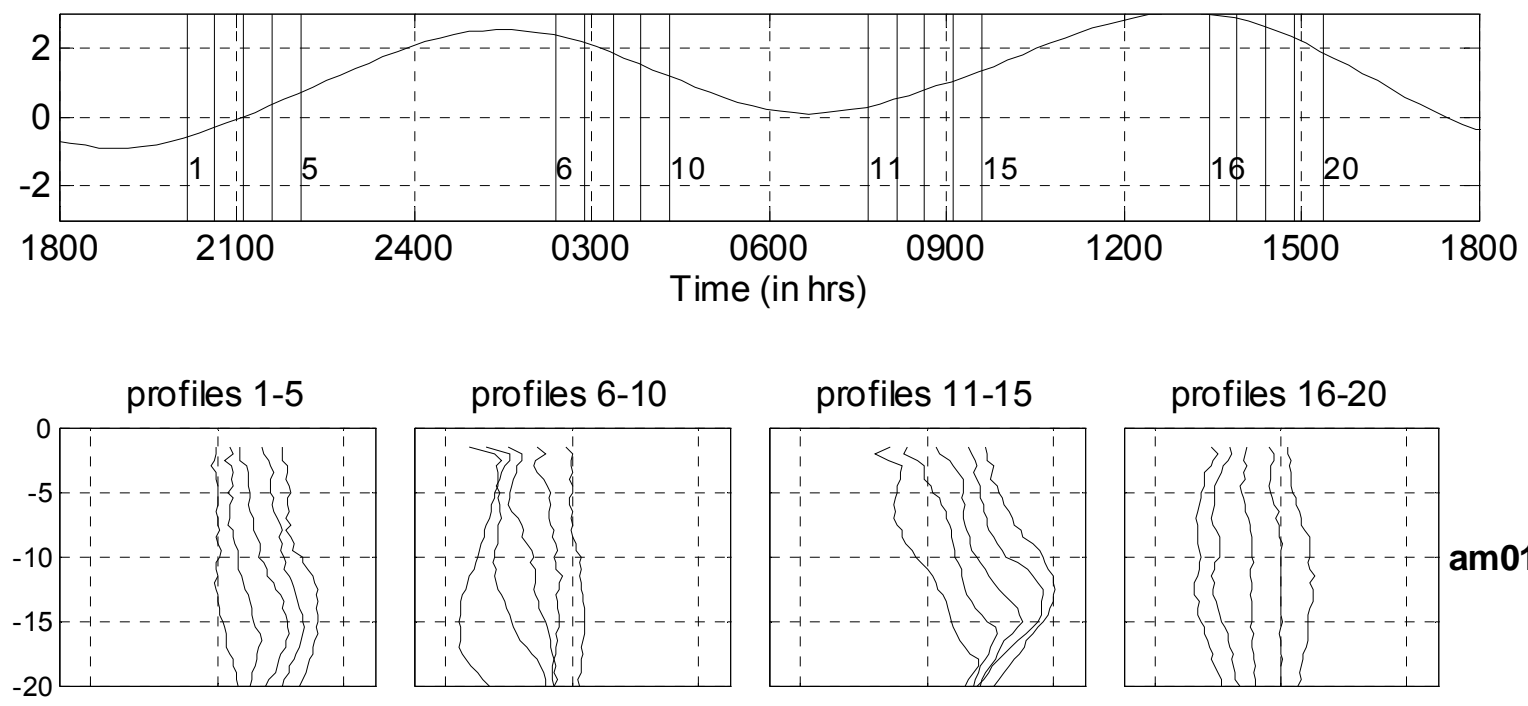

profiles $16-20$
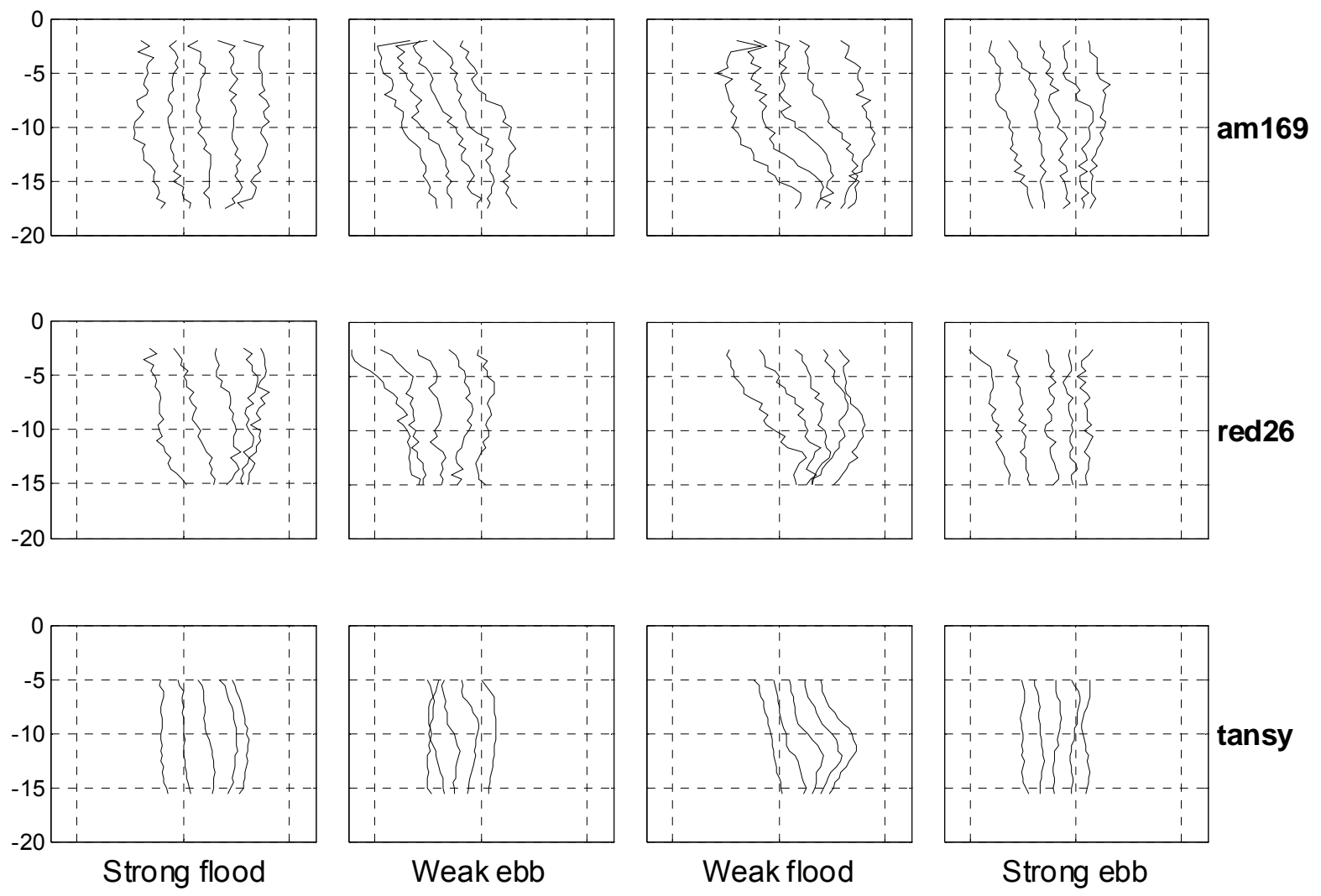

Figure 13 